\title{
The disturbance of gaze in progressive supranuclear palsy: implications for pathogenesis
}

\section{Athena L. Chen', David E. Riley ${ }^{2}$, Susan A. King' , Anand C. Joshi ${ }^{2}$, Alessandro Serra',2, Ke Liao', Mark L. Cohen ${ }^{3}$, Jorge Otero-Millan ${ }^{4}$, Susana Martinez-Conde ${ }^{4}$, Michael Strupp ${ }^{5}$ and R. John Leigh ${ }^{1,2 *}$}

\author{
1 Veterans Affairs Medical Center, University Hospitals Case Medical Center, Cleveland, OH, USA \\ 2 Neurological Institute, University Hospitals Case Medical Center, Cleveland, OH, USA \\ ${ }^{3}$ Department of Pathology, University Hospitals Case Medical Center, Cleveland, OH, USA \\ 4 Barrow Neurological Institute, Phoenix, AZ, USA \\ ${ }^{5}$ Department of Neurology and IFB-LMU, University of Munich, Munich, Germany
}

\section{Edited by:}

Adolfo M. Bronstein, Imperial College

London, UK

Reviewed by:

Dominik Straumann, University

Hospital Zurich, Switzerland

Alexandre Bisdorff, Centre Hospitalier

Emile Mayrisch, Luxembourg

${ }^{*}$ Correspondence:

R. John Leigh, Department of

Neurology, University Hospitals, 11100

Euclid Avenue, Cleveland

OH 44106-5040, USA

e-mail: rjl4@case.edu
Progressive supranuclear palsy (PSP) is a disease of later life that is currently regarded as a form of neurodegenerative tauopathy. Disturbance of gaze is a cardinal clinical feature of PSP that often helps clinicians to establish the diagnosis. Since the neurobiology of gaze control is now well understood, it is possible to use eye movements as investigational tools to understand aspects of the pathogenesis of PSP. In this review, we summarize each disorder of gaze control that occurs in PSP, drawing on our studies of 50 patients, and on reports from other laboratories that have measured the disturbances of eye movements. When these gaze disorders are approached by considering each functional class of eye movements and its neurobiological basis, a distinct pattern of eye movement deficits emerges that provides insight into the pathogenesis of PSP. Although some aspects of all forms of eye movements are affected in PSP, the predominant defects concern vertical saccades (slow and hypometric, both up and down), impaired vergence, and inability to modulate the linear vestibuloocular reflex appropriately for viewing distance. These vertical and vergence eye movements habitually work in concert to enable visuomotor skills that are important during locomotion with the hands free. Taken with the prominent early feature of falls, these findings suggest that PSP tauopathy impairs a recently evolved neural system concerned with bipedal locomotion in an erect posture and frequent gaze shifts between the distant environment and proximate hands. This approach provides a conceptual framework that can be used to address the nosological challenge posed by overlapping clinical and neuropathological features of neurodegenerative tauopathies.

Keywords: saccades, vergence, vestibular, parkinsonian disorders, tauopathy

\section{INTRODUCTION}

Since its original description (Steele et al., 1964), vertical gaze palsy has been recognized as a defining characteristic of progressive supranuclear palsy (PSP) that helps clinicians differentiate this disease from other parkinsonian disorders. Other cardinal clinical findings in PSP include falls early in the course of the disorder, dysphagia with choking, symmetric akinetic rigidity, absence of tremor, frontal lobe deficits, and lack of or only transient therapeutic response to dopaminergic medicines (Litvan et al., 1996; Williams and Lees, 2009). PSP is associated with a sporadic abnormality of the microtubule-associated protein tau, which is the main constituent of the neurofibrillary tangles (NFTs) that characterize a range of neurodegenerative disorders, collectively termed tauopathies (Dickson et al., 2010). The pathological distinction between PSP and other tauopathies, such as cortical-basal ganglionic (corticobasal) degeneration, has been largely based on the distribution of accumulation of abnormal tau protein throughout the brain (Williams and Lees, 2009). Therefore, it is not surprising that several autopsy studies, using the distribution and severity of tau protein load as the primary diagnostic criteria, have cast doubt on the sensitivity and specificity of the classic clinical findings of PSP and have led to the suggestion that there is an overlap between the different forms of tauopathy (Williams and Lees, 2009; Dickson et al., 2010). For example, it has been proposed that classic PSP be called Richardson's syndrome, and be distinguished from mixed presentations. These include: (1) PSP-parkinsonism (PSP-P), in which tremor may be present, falls and cognitive changes are not early features, and for which levodopa produces improvement; (2) PSP-corticobasal syndrome (PSP-CBS), in which asymmetric apraxia, cortical sensory loss, dystonia and lack of response to levodopa occur (Ling et al., 2010); (3) pure akinesia (PA) that affects speech, handwriting and gait, in the absence of tremor, limb rigidity or dementia, and levodopa responsiveness; and (4) PSP with progressive non-fluent aphasia (PSP-PNFA), which is distinguished by disturbance of the initiation, timing and flow of speech (Williams and Lees, 2009).

Here we bring a different approach to bear on the nature of PSP and related neurodegenerative disorders by harnessing the investigative power of eye movement research. Eye movements offer a number of advantages in such ventures (Leigh and Zee, 2006; Kennard and Leigh, 2008). First, they can be measured with precision. Second, the relationship between eye rotations and the discharge of ocular motoneurons is direct and relatively simple. Third, several functional classes of eye movements can be identified (Table 1), each of which possesses properties that suit it for specific purposes. Fourth, much is now known about the anatomy, physiology, and pharmacology of each functional class of eye movements. By applying a "bottom-up" approach (Figure 1A), 
Table 1 | Functional classes of human eye movements.

\begin{tabular}{ll}
\hline Class of eye movement & Main function \\
\hline $\begin{array}{l}\text { Fixation } \\
\text { Vestibulo-ocular reflexes (VOR) }\end{array}$ & $\begin{array}{l}\text { Holds the image of a stationary object on the fovea by minimizing ocular drifts } \\
\text { Holds images of the seen world steady on the retina during brief head rotations (angular VOR) or linear } \\
\text { movements (linear VOR) } \\
\text { Ocular following responses (OFR) }\end{array}$ \\
$\begin{array}{l}\text { Short-latency response to motion of the visual scene; represents early motion processing. } \\
\text { Smooth pursuit }\end{array}$ & $\begin{array}{l}\text { Hold images of the visual world steady on the retina during sustained head rotation } \\
\text { Holds the image of a small moving target on the fovea - requiring directed visual attention; can be used } \\
\text { to negate the angular vestibulo-ocular reflex during combined eye-head smooth tracking }\end{array}$ \\
Saccades & $\begin{array}{l}\text { Reset the eyes during prolonged rotation and direct gaze toward the oncoming visual scene } \\
\text { Vergence }\end{array}$ \\
& $\begin{array}{l}\text { Rapidly bring images of objects of interest onto the fovea } \\
\text { Moves the eyes in opposite directions so that images of a single object are placed or held } \\
\text { simultaneously on the fovea of each eye }\end{array}$ \\
\hline
\end{tabular}
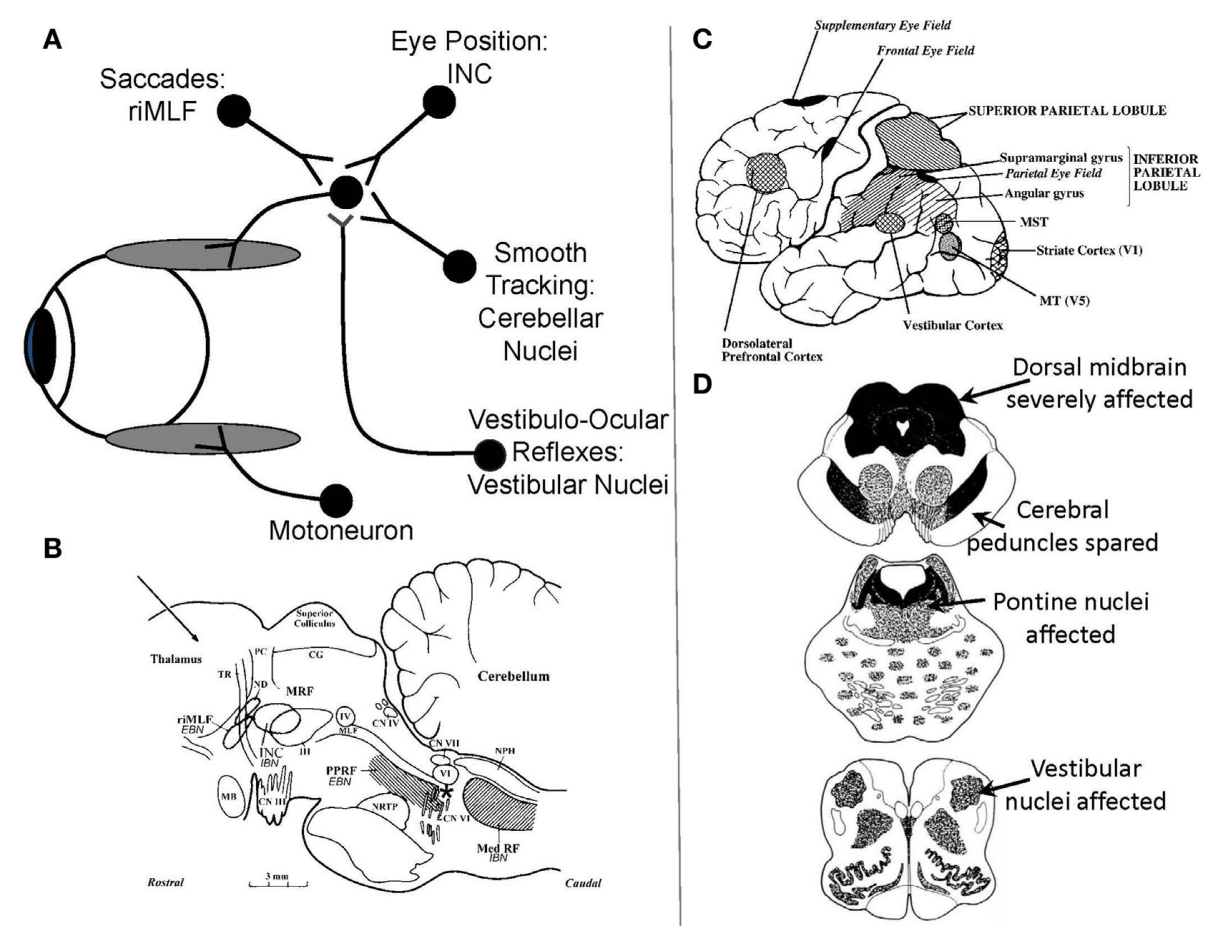

FIGURE 1 | (A) Schematic summary of main premotor inputs to motoneurons innervating vertically acting extraocular muscles. riMLF, rostral interstitial nucleus of the medial longitudinal fasciculus; INC, interstitial nucleus of Cajal. See text for commentary. (B) Sagittal section of the monkey brain stem showing the locations of premotor burst neurons: excitatory burst neurons (EBN) for horizontal saccades lie in the paramedian pontine reticular formation (PPRF); inhibitory burst neurons (IBN) for horizontal saccades lie in the medullary reticular formation (Med RF); EBN for vertical and torsional saccades lie in the rostral interstitial nucleus of the medial longitudinal fasciculus (riMLF). Some vertical IBN may reside in or close to the interstitial nucleus of Cajal (INC). EBN and IBN project to ocular motoneurons lying in the abducens nucleus (VI), the trochlear nucleus (IV) and the oculomotor nucleus (III). Omnipause neurons (indicated by an asterisk) lie in the midline raphe of the pons between the rootlets of the abducens nerve (CNVI) and gate the activity of EBN and IBN. The mesencephalic reticular formation (MRF) may also contribute to vertical saccades. CG, central gray; MB, mammillary body; CN III, rootlets of the oculomotor nerve; CN IV, trochlear nerve; ND, nucleus of Darkschewitsch; NRTP, nucleus reticularis tegmenti pontis; $\mathrm{PC}$, posterior commissure; $\mathrm{NPH}$, nucleus prepositus hypoglossi; sc, superior colliculus; TR, tractus retroflexus. The arrow refers to the Horsley-Clarke plane of section. Figure courtesy of Dr. Jean Büttner-Ennever. (C) Probable location of cortical areas important for eye movements in human brain. MST, medial superior temporal visual area; MT, middle temporal visual area. Adapted from Leigh and Zee (2006) with permission. (D) Figures adapted with permission from Steele et al. (1964) that summarize the brainstem regions affected in PSP; the intensity of shading corresponds to the severity of the involvement. it is possible to relate specific abnormalities in PSP to identified brainstem circuits. Taking these features together, measurement of eye movements not only provides a powerful research tool but also empowers the clinician who understands certain basic properties of the ocular motor system. Finally, by considering the role of eye movements in normal visuomotor behavior, it is possible to develop a hypothesis to account for the unusual constellation of findings that characterizes PSP. 
In this review, we summarize our studies of approximately 50 patients with PSP and related neurodegenerative disorders over the past 20 years. We also draw on work from other laboratories that have made reliable measurements of eye movements, a challenging task in patients with PSP.

Normal persons point the fovea (macula) of their retina at a visual target, because this provides their highest visual acuity. It follows that, when instructed, normal study subjects can be counted on to voluntarily direct their foveal line of sight at targets and produce a dependable calibration of eye movement signals. In contrast, most PSP patients cannot accurately and consistently point their foveal line of sight, because of their defect in voluntary gaze. Thus, measurements that depend on visually driven eye movements for calibration are inherently unreliable in patients with PSP. We have used the search coil/magnetic field technique in all of our studies of PSP over the past 25 years (Robinson, 1963; Leigh and Zee, 2006). Since the search coil, which consists of a coil of wire embedded in a silastic annulus, can be calibrated on a protractor before it is placed on a patient's eye, it provides reliable measurements with a sensitivity of $0.05^{\circ}$, a linear operating range of up to $360^{\circ}$, and a bandwidth of $0-150 \mathrm{~Hz}$.

Although all functional classes of eye movements (Table 1) may be affected in PSP, we start by presenting our findings concerning saccades in some detail, since these normally rapid eye movements are most prominently affected clinically. Our cumulative studies of saccades in PSP have not been previously published as one group of 30 patients and, therefore, we describe our subjects and methods of analysis for this component of the review. We then discuss each of the other functional classes in turn, referring to previously published papers to provide information about subjects and methodologies. For each functional class of eye movements, we first describe the behavioral changes that have been reported and then provide a neurobiological scheme that may account for the observed disorders of eye movements. Finally, we develop a hypothesis for the pathogenesis of PSP by asking what general disturbance of visuomotor behavior is affected and what underlying disturbance could account for it.

\section{FAST EYE MOVEMENTS: SACCADES AND QUICK PHASES OF NYSTAGMUS \\ PROPERTIES AND SUBSTRATE FOR SACCADES}

Saccades are rapid eye movements that redirect the foveal line of sight toward features of interest that can then be seen optimally (Leigh and Zee, 2006). Quick phases of nystagmus are the evolutionary forerunners of saccades, providing a resetting mechanism for the eyes during sustained vestibular or optokinetic stimulation. Both saccades and quick phases are generated by the same brainstem machinery (Figure 1B; Horn, 2006). For vertical saccades and quick phases, ocular motoneurons innervating vertically acting extraocular muscles (Figure 1A) receive the premotor signal - a burst of innervation - from neurons in the rostral interstitial nucleus of the medial longitudinal fasciculus (riMLF), which lies in the prerubral fields of the rostral midbrain (Horn and Buttner-Ennever, 1998). Burst neurons for upward saccades project bilaterally to motoneurons supplying elevator extraocular muscles; burst neurons for downward saccades project ipsilaterally to motoneurons supplying depressor extraocular muscles (Moschovakis et al., 1991a,b).
For horizontal saccades and quick phases, ocular motoneurons innervating the horizontal rectus extraocular muscles receive the premotor signal from burst neurons in the paramedian pontine reticular formation (PPRF; Horn et al., 1997). Bilateral experimental lesions of riMLF abolish vertical saccades and quick phases (as well as torsional quick phases), but leave other forms of eye movement intact (Suzuki et al., 1995). As is evident from Figure 1D, top section, the riMLF is affected early in the course of PSP; the PPRF is affected later. MRI studies in PSP show atrophy of the midbrain with dilatation of the quadrigeminal cisterns, aqueduct and third ventricle, giving the characteristic "hummingbird" sign (Kato et al., 2003).

Another midbrain structure that contributes to the generation of normal vertical saccades is the interstitial nucleus of Cajal (INC; Kokkoroyannis et al., 1996). Electrophysiological and inactivation studies of INC implicate it in the important role of "gaze holding" - sustaining the eye at a specific position once it has arrived there. Besides generating the essential "position signal" (Figure 1A) for holding gaze steady, INC also contributes to vertical vestibular responses and vertical saccades, since some burst neurons, possibly inhibitory, reside in INC (Horn, 2006). Experimental inactivation of INC restricts the range of vertical saccades without affecting their speed (Helmchen et al., 1998). The INC is also affected in PSP, which may account for the limited range of voluntary upward or downward voluntary saccades that occurs in PSP.

Saccades occur under a range of conditions, and different types of fast eye movements can be identified and classified on the basis of their behavioral properties (Table 2). Common to all - from the most reflexive type (quick phases of nystagmus) to the most volitional (saccades to remembered or imagined targets) - is that they are generated by the brainstem neural circuits that are especially affected in PSP. Quick phases of nystagmus induced by optokinetic stimulation are slow and small in the vertical plane in PSP patients; they are often oblique in direction, being made in combination with horizontal square-wave jerks (SWJ; Garbutt et al., 2004). A number of studies have addressed the issue of initiation of saccades in PSP, sometimes demonstrating increased reaction time (latency) of horizontal saccades (Garbutt et al., 2008), but other times demonstrating retained ability to make short-latency "express saccades" when the fixation light is turned out before the target is presented (gap stimulus; Pierrot-Deseilligny et al., 1989). Vertical saccades, however, may be made at increased latency (Garbutt et al., 2008). When patients with PSP are required to look in the opposite direction to a suddenly appearing target - the antisaccade task (Leigh and Kennard, 2004) - they make more directional errors (Garbutt et al., 2008), a pattern that is consistent with frontal lobe dysfunction. Specifically, dorsolateral prefrontal cortex seems important for preventing an inappropriately directed saccade and the frontal eye field for initiating the appropriate movement (Figure 1C; PierrotDeseilligny et al., 2003). Higher-level control of saccades depends on projections from the frontal and parietal eye field (Figure 1C) to the superior colliculus, including basal ganglionic loops; the reader is referred to other reviews for details (Leigh and Kennard, 2004; Leigh and Zee, 2006). In general, more reflexive saccades depend on projections from the parietal eye field to the superior colliculus, whereas more voluntary saccades are dependent on descending pathways from the frontal eye field. The supplementary eye field, 
Table 2 | Classification of saccades.

\begin{tabular}{|c|c|}
\hline Classification & Definition \\
\hline Quick phases & $\begin{array}{l}\text { Generated during vestibular or optokinetic stimulation or as automatic resetting movements in the presence of } \\
\text { spontaneous drift of the eyes. }\end{array}$ \\
\hline Spontaneous saccades & Random saccades occurring if the subject is not required to perform any particular behavioral task. \\
\hline Microsaccades or fixational saccades & Small amplitude saccades that occur spontaneously during attempted visual fixation \\
\hline Express saccades & $\begin{array}{l}\text { Very short-latency saccades that can be elicited when the novel stimulus is presented after the fixation stimulus } \\
\text { has disappeared (gap stimulus) }\end{array}$ \\
\hline Reflexive saccades & Saccades generated to novel stimuli (visual, auditory or tactile) that unexpectedly occur within the environment. \\
\hline Voluntary saccades & Elective saccades made as part of purposeful behavior or to verbal command \\
\hline Predictive, anticipatory & Saccades generated in anticipation of or in search of the appearance of a target at a particular location. \\
\hline Memory-guided & Saccades generated to a location in which a target has been previously present. \\
\hline Antisaccades & Saccades generated in the opposite direction to the sudden appearance of a target. \\
\hline
\end{tabular}

located parasagittally (Figure 1C), seems important for learning sequences of motion and changing instructional set (Nachev et al., 2008).

In PSP frontal and parietal lobes are typically affected by the tau pathology, but occipital-temporal cortex is relatively spared (Williams and Lees, 2009). Disturbance of the higher-level control of saccades is best studied in the laboratory, but here we focus on slowing and restricted range of movement of saccades made to visual stimuli, since this corresponds closely with findings on the bedside examination.

\section{SUBJECTS AND METHODS FOR SACCADE STUDIES}

We analyzed records from a group of 30 patients (12 male) with PSP studied over a period of two decades, using the search coil/ magnetic field technique (Rottach et al., 1996; Liao et al., 2008b; Joshi et al., 2010). Their age range was 49-77 years $($ mean $=68.3)$ and the diagnosis was probable (27) or definite (3) PSP diagnosed by NINDS/SPSP criteria (Litvan et al., 1996). Their disease duration was $0.5-7$ years (mean $=3.6$ ); their demographic details are summarized in Table 3. We also studied 10 healthy control subjects (age range $60-79$ years, mean $=68.4$ ). All subjects provided informed, written consent in accordance with our Institutional Review Board and the Declaration of Helsinki. In addition to magnetic search coil measurements, we carried out clinical evaluations of saccades, smooth pursuit, vestibulo-ocular reflex, and overall gaze palsy in 26 of these 30 PSP patients, based on independent scoring of video records by three observers (two naïve to the results of quantitative analysis), referring to a previously described scale (Rivaud-Pechoux et al., 2000). For each PSP patient, a consensus was sought as to whether the predominant direction of the saccadic palsy was up or down, and when observers disagreed or were uncertain, the vertical saccadic palsy was designated symmetric. For the remaining four patients, the investigator's notes regarding eye movements were reviewed.

Patients and control subjects were instructed to look at visual targets presented on a tangent screen located $1.2 \mathrm{~m}$ from where they sat; in order to foveate the targets, vertical or horizontal saccades, $5^{\circ}$ to $40^{\circ}$ in amplitude, over the range $\pm 20^{\circ}$ from center position, were required. Patients and subjects were provided with verbal encouragement to follow the target jumps and, for patients with more advanced disease, the investigator pointed to target locations.
Velocity of saccades. To study the velocity of saccades, we created "main sequence" plots of peak velocity versus amplitude and used two-parameter power curves, of the form

Peak velocity $=K \times$ amplitude ${ }^{L}$

where $K$ is a scaling factor and $L$ is the power, to fit the data for each subject or patient. This power fit is more reliable than an exponential fit for analysis of smaller saccades, which occur in patients with PSP (Garbutt et al., 2003). In calculating group results, we only analyzed the peak velocity/amplitude relationships of saccades from patients $(n=17$; mean age $=66.9$ years, mean duration $=3.1$ years $)$ and control subjects $(n=10)$ for whom both upward and downward power curve fits had $R^{2}>0.7$. We then used paired comparisons of the fit terms $K$ and $L$ to determine whether there was a difference between upward and downward saccades for the 10 controls and 17 PSP patients. We also compared the values of the $K$ and $L$ ratios $K_{\text {upward }} / K_{\text {downward }}$ and $L_{\text {upward }} / L_{\text {downward }}$ for the patients separated into two groups based on disease duration, one group with duration $<2.75$ years $(n=8)$ and the other group with duration $>2.75$ years $(n=9)$.

Size of saccades. We applied two methods to compare the sizes of upward and downward saccades. First, we measured the gain of saccades to target jumps in 10 PSP patients (mean age $=70.2$ years, mean duration $=3.1$ years) and our 10 control subjects. We defined gain as amplitude of initial saccade/amplitude of final gaze shift. We conducted paired comparisons of upward versus downward gain measurements for each individual. Second, we compared the amplitudes of the upward and downward saccades made by every individual in our study (patient or control) in response to the target jumps, which comprised symmetric up-down displacements. We also tested whether vertical saccades remained conjugate by applying the technique of binocular phase plane analysis (Serra et al., 2008).

Asymmetry of saccades. Finally, we asked how well our clinical estimates of the asymmetry of vertical saccadic palsy (limited range of movements and observed slowing of saccades) corresponded to measurements of peak velocity for individual PSP patients, judged from their data fits by Eq. 1 . We identified velocity asymmetry when the value of the ratio $L_{\text {upward }} / L_{\text {downward }}$ was $<0.8$ or $>1.2$, since parameter $L$ is predominantly affected by larger saccades that would be more evident during the clinical examination. 
When the distribution of data was normal, we used $t$-tests and one-way ANOVA; when data were not normal, we used nonparametric statistics (Mann-Whitney Rank Sum test, Wilcoxon test, ANOVA on ranks). To test the concordance of clinical estimates of saccadic gaze palsy with saccadic peak velocity, we calculated Fleiss' kappa.

\section{RESULTS OF SACCADE STUDY}

\section{Clinical abnormalities of saccades}

Slowing of vertical saccades was a consistent finding in all PSP patients, usually in both directions. Limited range by saccadic movements was judged to be more marked upward in 14 patients and downward in 7; in 9 patients the saccadic palsy was symmetric (Table 3). Figure 2 shows representative upward and downward saccades made by a 67-year-old female control subject (A) and a 69-year-old male with definite PSP (disease duration 2 years) (C); corresponding plots of peak velocity versus amplitude are shown in Figures 2B,D. It is apparent that saccades made by the PSP patient are smaller and slower than those made by the control subject. Clinically, this patient's saccadic palsy was judged to be worse for upward movements; the measured velocity of his vertical saccades (Figure 2D) showed smaller saccades to be, however, faster upwards but larger saccades to be faster downwards.

\section{Velocity of saccades}

We conducted a paired comparison of the values of the terms in Eq. 1, describing the peak velocity/amplitude relationship of upward and downward saccades made by control subjects

Table 3 | Summary of patient demographics, medications, and saccadic palsy evaluations.

\begin{tabular}{|c|c|c|c|c|c|}
\hline Patient no. & $\mathrm{Age}^{*}$ & Sex & Duration* & Drugs & $\begin{array}{l}\text { Saccadic palsy (clinical/ } \\
\text { main sequence)** }\end{array}$ \\
\hline 1 & 74 & $\mathrm{M}$ & 7 & None & Worse down/worse down \\
\hline 2 & 72 & $\mathrm{~F}$ & 3 & Bupropion & Symmetric/symmetric \\
\hline 3 & 70 & $\mathrm{~F}$ & 2 & Carbidopa/levodopa & Worse down/symmetric \\
\hline 4 & 70 & $\mathrm{M}$ & 7 & Carbidopa/levodopa & Worse down/symmetric \\
\hline 5 & 49 & $\mathrm{M}$ & 1 & Amantadine & Symmetric/symmetric \\
\hline 6 & 72 & $\mathrm{~F}$ & 2 & Carbidopa/levodopa, rasagiline & Worse up/worse up \\
\hline 7 & 69 & $\mathrm{M}$ & 2 & None & Worse up/worse up \\
\hline 8 & 61 & $\mathrm{M}$ & 4 & None & Worse up/worse up \\
\hline 9 & 64 & $\mathrm{~F}$ & 3 & Amantadine, verapamil & Worse up/symmetric \\
\hline 10 & 74 & $\mathrm{~F}$ & 3.5 & Amantadine, paroxetine, trazodone & Symmetric/symmetric \\
\hline 11 & 67 & $\mathrm{~F}$ & 5 & Carbidopa/levodopa, donepezil & Worse up/worse up \\
\hline 12 & 64 & $\mathrm{~F}$ & 5.5 & Bupropion, temazepam & Worse down/worse up \\
\hline 13 & 76 & $\mathrm{~F}$ & 3 & Benazepril & Worse up/worse up \\
\hline 14 & 61 & $\mathrm{~F}$ & 4.5 & Carbidopa/levodopa & Worse up/symmetric \\
\hline 15 & 75 & $\mathrm{M}$ & 5 & Carbidopa/levodopa & Worse down/worse down \\
\hline 16 & 71 & $\mathrm{M}$ & 4 & None & Worse up/worse down \\
\hline 17 & 74 & $\mathrm{~F}$ & 4 & Carbidopa/levodopa, galantamine & Worse up/symmetric \\
\hline 18 & 71 & $\mathrm{M}$ & 5 & Amlodipine, donepezil, sertraline & Worse up/symmetric \\
\hline 19 & 76 & $\mathrm{~F}$ & 7 & None & Worse up/symmetric \\
\hline 20 & 64 & $\mathrm{M}$ & 6 & None & Worse up/worse down \\
\hline 21 & 66 & $\mathrm{M}$ & 2 & Atenolol, buspirone, simvastatin & Symmetric/symmetric \\
\hline 22 & 77 & $\mathrm{~F}$ & 3 & None & Symmetric/worse up \\
\hline 23 & 63 & $\mathrm{~F}$ & 5 & Bupropion, duloxetine, valproate & Worse up/worse up \\
\hline 24 & 61 & $\mathrm{~F}$ & 3 & $\begin{array}{l}\text { Alprazolam, amantadine, metformin, } \\
\text { pramipexole }\end{array}$ & Worse down/worse down \\
\hline 25 & 63 & $\mathrm{M}$ & 0.5 & Carbidopa/levodopa & Worse up/worse up \\
\hline 26 & 69 & $\mathrm{~F}$ & 2.5 & Mirtazapine & Symmetric/symmetric \\
\hline 27 & 63 & $\mathrm{~F}$ & 1.5 & Zolpidem & Symmetric/symmetric \\
\hline 28 & 74 & $M$ & 5 & None & Symmetric/worse up \\
\hline 29 & 68 & $\mathrm{~F}$ & 2.5 & Sertraline & Worse down/worse down \\
\hline 30 & 70 & $\mathrm{~F}$ & 2 & Amantadine & Symmetric/worse up \\
\hline
\end{tabular}

*Age and duration of disease are given in years.

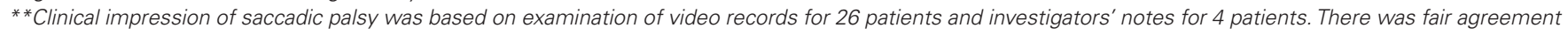

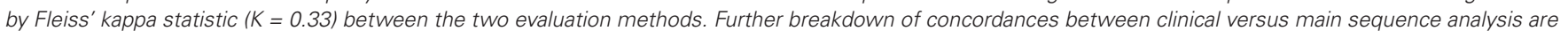

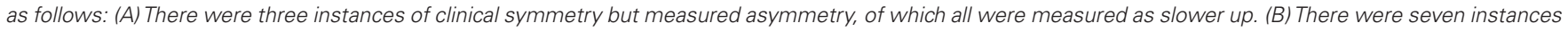

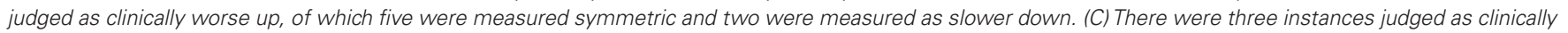
slower down, of which two were measured symmetric and one was measured worse up. Thus, down versus up disagreements occurred in only three cases. 

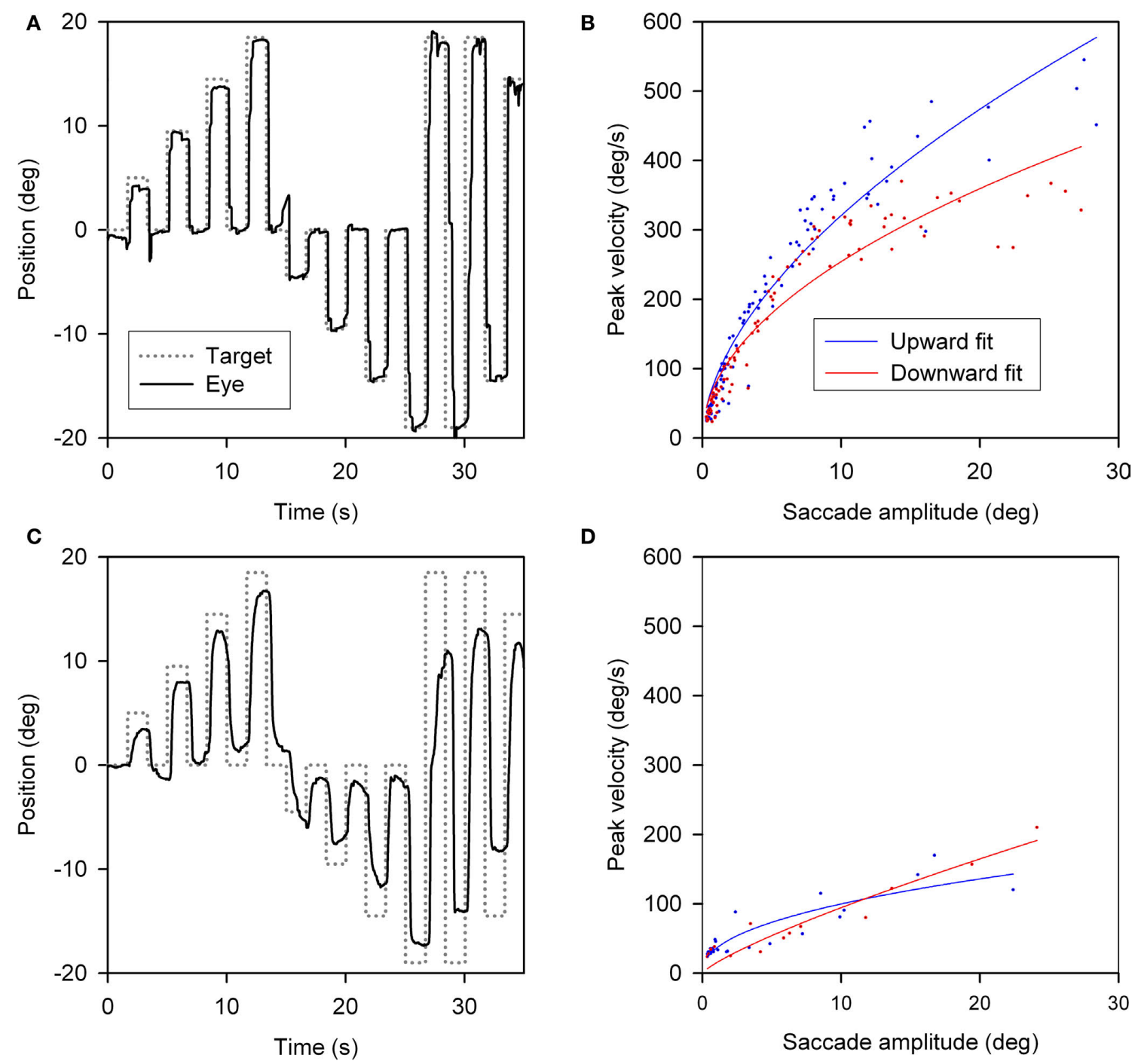

D

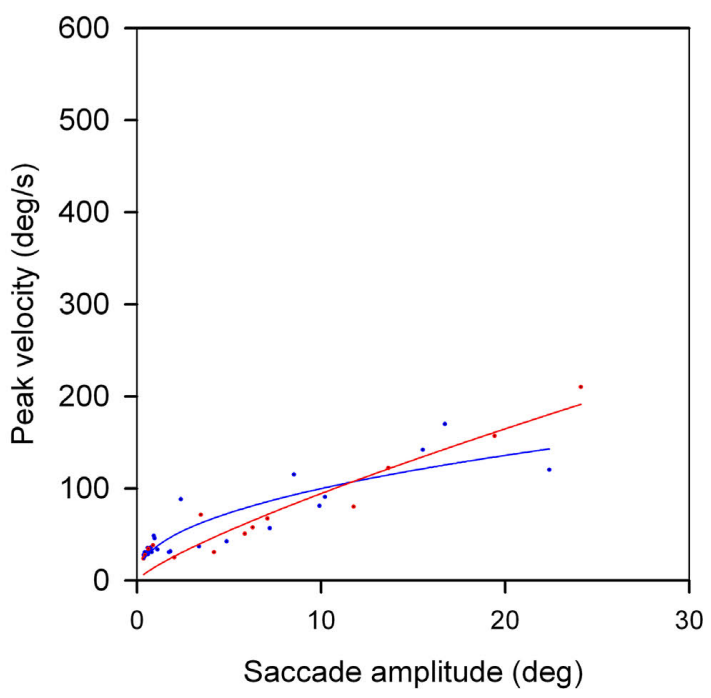

FIGURE 2 |Vertical saccades made by a normal subject and a patient with PSP. (A) Representative healthy elderly subject's target-directed vertical saccades. (B) Peak velocity-amplitude relationship of these saccades, as modeled by the equation (peak velocity $=K \times$ amplitude ${ }^{L}$ ). Both fit curves have

$R^{2}>$ 0.9. This particular subject made faster upward saccades than downward saccades. (C) PSP patient's saccades to similar target jumps as for the control in (A). (D) PSP patient's peak velocity-amplitude fit curves; both have $R^{2}>0.75$. The curve fits for this PSP patient's upward and downward saccades show overlap.

and 17 PSP patients with curve fits $R^{2}>0.7$. Figure $3 \mathrm{~A}$ displays 5 and $95 \%$ prediction intervals for 10 control subjects based on all 1,856 of their vertical saccades $\left(n_{\text {up }}=1020, n_{\text {down }}=836\right)$, since paired $t$-tests detected no differences between upward and downward $K$ - and $L$-values ( $p=0.635$ and 0.459 ). Figure 3A also shows all upward $(n=990)$ and downward $(n=805)$ saccades made by 17 PSP patients. For patients, paired $t$-tests showed no difference for $K_{\text {up }}$ versus $K_{\text {down }}(p=0.920)$ or $L_{\text {up }}$ versus $L_{\text {down }}$ $(p=0.128)$. Both upward and downward saccades made by patients were slower than those made by age-matched control subjects: mean $K$-values were 50.161 for patients and 73.583 for controls $(p<0.001)$; the median $L$-value was 0.445 for patients and 0.529 for controls $(p=0.013)$, see Figures 3C,D. We also compared peak velocity/amplitude relationships for centripetal versus centrifugal saccades in the upper and lower hemifields of movement using ANOVA on ranks, and found no difference between any group $(p=0.781)$.

When we asked whether disease duration had an effect on patients' $K$ - and $L$-values, we found no difference between the shorter (less than 2.75 years) and longer (greater than 2.75 years) duration groups' $K_{\text {upward }} / K_{\text {downward }} \operatorname{ratios}(p=0.532)$ or $L_{\text {upward }} / L_{\text {downward }}$ ratios $(p=0.112)$.

Finally, we also compared rightward versus leftward horizontal saccades and found no difference for either control subjects or PSP patients (Figure 3B). However, the latter group made moderately slower saccades in either direction than did control subjects: for controls and patients, mean $K$-values were 88.336 versus 78.536 $(p=0.045)$ and mean $L$-values were 0.492 versus $0.41(p<0.001)$. 

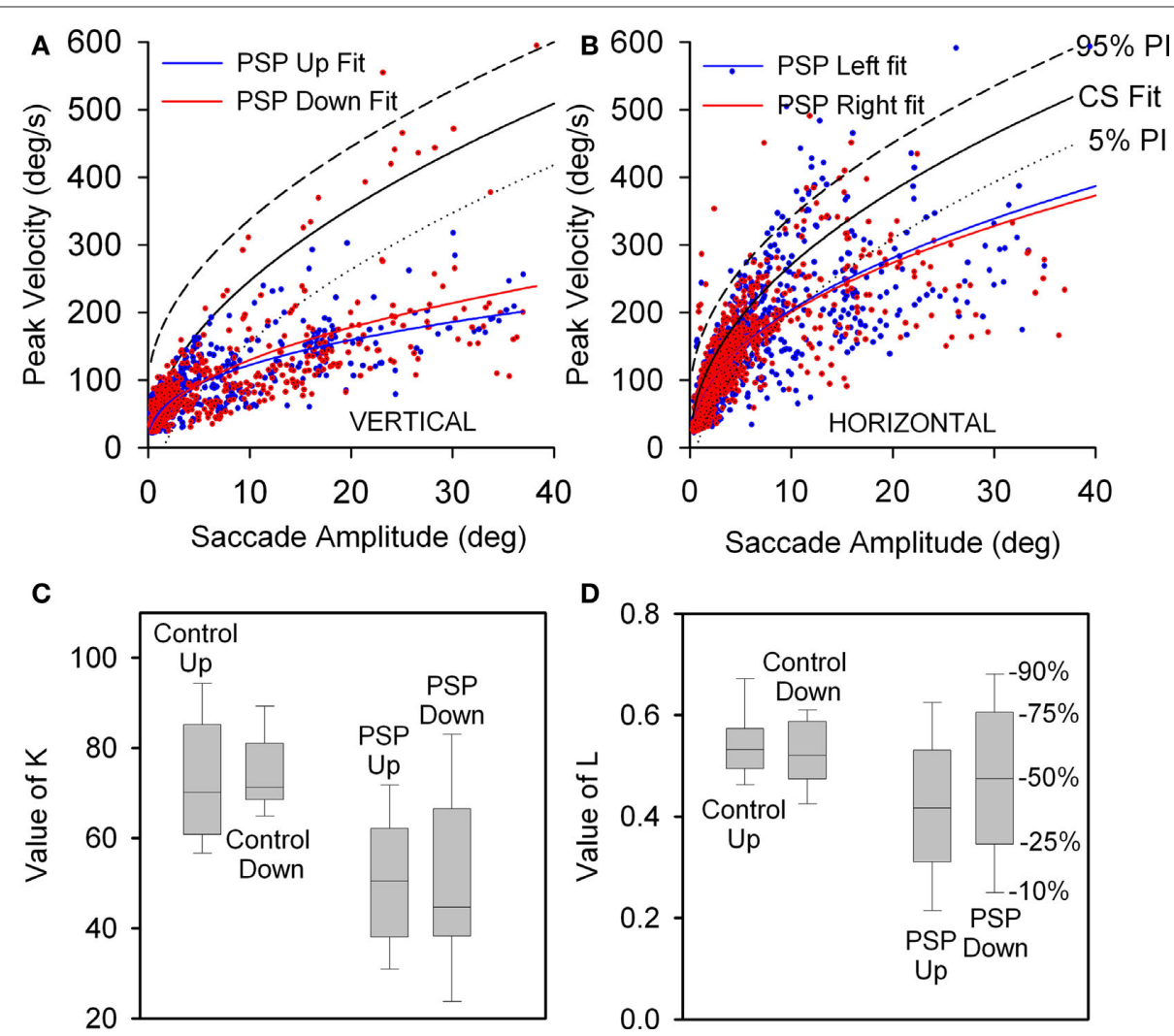

FIGURE 3 | Peak velocity-amplitude relationship of vertical saccades (A) and horizontal saccades (B) made by control subjects (CS) and PSP patients. (A) Upward and downward power fits calculated for all vertical saccades made by 17 PSP patients for whom $R^{2}>0.7$. Fit, 5 and $95 \%$ prediction interval (PI) for all CS saccades are shown. Most of the faster downward saccades were made by one patient with 1.5 year disease duration. (B) Horizontal saccades made by PSP patients were slower than those made by CS

Vertical saccades were substantially slower than horizontal saccades (compare Figures 3A,B), consistent with prior clinical and laboratory studies of PSP.

\section{Gain and size of saccades}

For 3 of 10 control subjects, the gain of downward saccades was significantly greater than that of upward saccades. Furthermore, a paired comparison of the 10 control subjects found that downward gain was larger $(p=0.006)$. Two of 10 PSP patients showed differences between upward and downward gain: one had greater gain for downward saccades $(p=0.02)$ and the other for upward saccades $(p=0.002)$. A paired comparison of mean gain values for each of the 10 PSP patients showed no difference between up and down $(p=0.789)$. The gain of saccades made by PSP patients was smaller than controls' gain for both upward $(p=0.009)$ and downward $(p=0.001)$ movements. These results are summarized in Figure 4A. We also compared the gain of similar-sized saccades for centripetal versus centrifugal movements in the upper and lower hemifields of movement and found no significant difference between any groups. Since saccades to small target jumps often have larger gains than saccades to larger target jumps, we also compared larger $\left(>8^{\circ}\right)$ centrifugal saccades up versus down; there was no significant difference.

Next we compared the amplitudes of all upward versus downward saccades made by the 30 PSP patients and the 10 control subjects. Pooled data are summarized in Figure 4B. Six of 10 control subjects showed no difference, while the other four all made significantly larger downward saccades. Pooled data from all 10 control subjects exhibited larger downward movements $(p<0.001)$. Of our 30 PSP patients, there were six individuals whose median downward saccade amplitude was significantly larger than their median upward saccade amplitude and one individual for whom the opposite was true. Comparison of all upward or downward saccades made by PSP patients (upward = 1606; downward $=1424$ ) and control subjects using ANOVA on ranks showed that saccades in either direction made by PSP patients were smaller than those of control subjects, and that downward saccades were larger than upward saccades $(p<0.05)$.

We also looked for disconjugacy of vertical saccades, which usually points to a disorder in the peripheral ocular motor system, either at a nerve, a muscle or the neuromuscular junction 


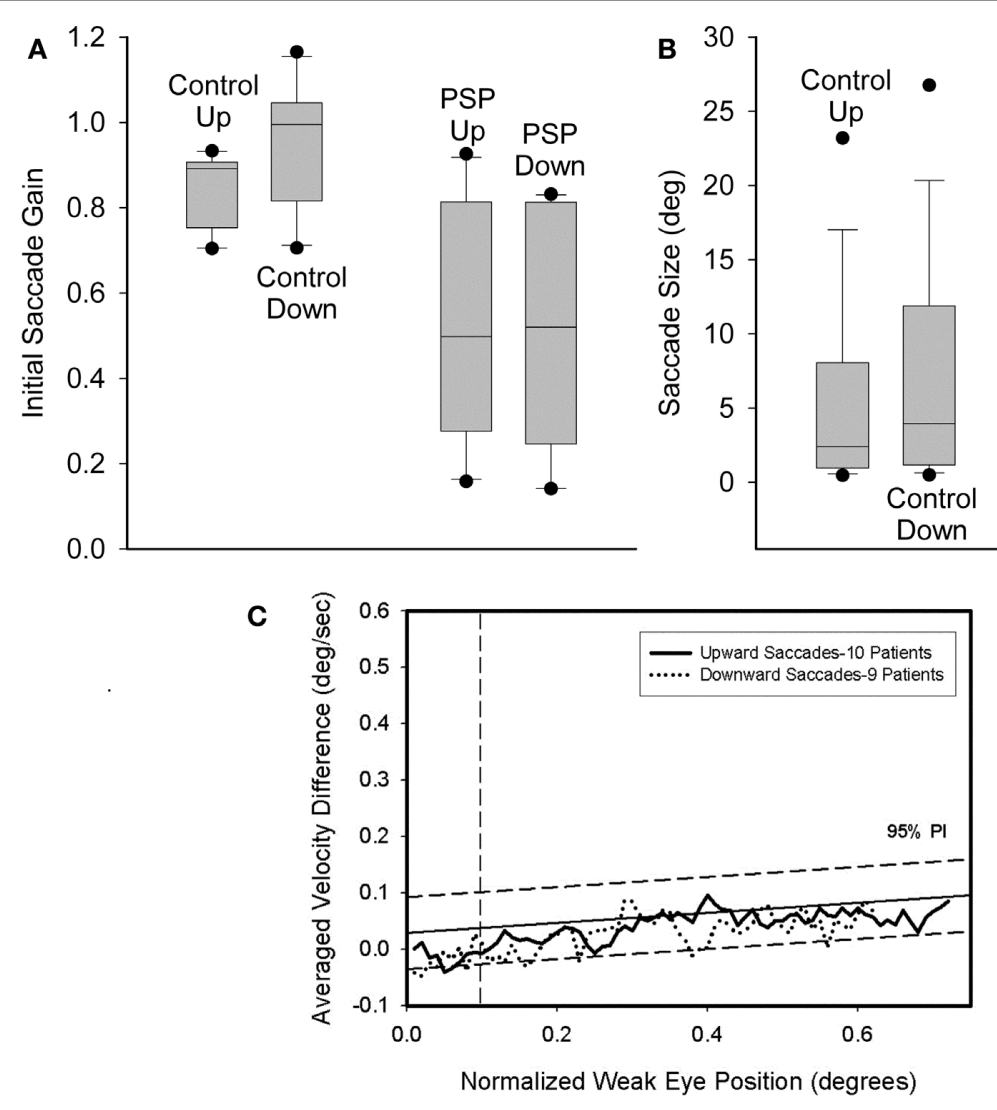

FIGURE 4 | Comparison of size of vertical saccades made by controls and PSP patients. (A) Gain comparison. Downward gain was larger than upward gain for our 10 control subjects ( $p=0.006$ ), but there was no difference for the 10 PSP patients tested. (B) Amplitude comparison. Downward saccade size was larger than the upward saccade size for both the elderly control $(p<0.001)$ and PSP patient $(p=0.002)$ groups. Box-plot symbols are similar to Figure 3; dot symbols represent 5 and $95 \%$ percentiles. (C) Conjugacy of vertical saccades made by PSP patients using the approach of binocular phase planes. The abscissa scale is normalized eye displacement. The ordinate scale is the difference in normalized eye speed between the two eyes. The dashed lines are 5 and 95\% prediction intervals (PI) based on over a thousand saccades made by 10 normal subjects. Although PSP patients made slower vertical saccades than control subjects, their eye movements are tightly conjugate. site. Comparison of the conjugacy of vertical saccades using phase plane analysis was possible in 9 PSP patients (Serra et al., 2008). We found no asymmetry of upward or downward movements. In both cases, conjugacy was similar to control subjects (Figure 4C). This is consistent with symmetric involvement of midbrain vertical gaze centers in PSP.

\section{Concordance of clinical findings and saccadic measurements}

Finally, we asked whether our clinical evaluations of the asymmetry of patients' saccadic gaze palsy were in accord with measured asymmetries of peak velocity-amplitude relationships for each individual PSP patient (Table 3). We found that asymmetry of peak velocity agreed with the clinical estimate of saccadic palsy (limited range of movement and observed slowing of saccades) in $17 / 30$ patients. When we examined the 13 conflicts between clinical impressions and peak velocity measurements, we found there were only three instances when clinical judgment and velocity measurements were in opposite directions. Formal statistical analysis is summarized in Table 3.

\section{INTERPRETATION OF THE DISTURBANCE OF SACCADES IN PSP}

At the bedside, two prominent defects of vertical saccades are evident in patients with PSP: restricted range of movement and slowing. Any analysis of limited vertical saccadic range in PSP must take into account the late age of onset of this disorder, since progressive limitation of the vertical range of eye movements, especially upward, occurs in healthy subjects after age 60 years (Clark and Isenberg, 2001; Oguro et al., 2004). This limitation has been attributed to biomechanical changes in the orbital fascia (Clark and Demer, 2002). Conversely, age is accompanied by only small differences in the speed of upward and downward saccades in healthy older individuals (Huaman and Sharpe, 1993), and histopathological studies indicate no loss of riMLF burst neurons with age (Henson et al., 2003).

Following the original descriptions of PSP, many clinicians look especially for a voluntary inability to look down (Steele et al., 1964; Williams et al., 2008). Clinically, upward saccadic palsy occurred twice as often as downward saccadic palsy in our group of 30 PSP patients. Based on reliable measurements of eye movements, we 
found no overall up-down asymmetry in the speed of vertical saccades in the range $\pm 20^{\circ}$ of center position. The gain of initial saccades to upward or downward target jumps was not different in our PSP patients. The size of all pooled downward saccades was greater than all pooled upward saccades in both patients and control subjects; a similar bias has been previously noted in normal subjects (Collewijn et al., 1988). These results are consistent with results from another laboratory that measured vertical eye movements in PSP and reported no vertical asymmetry of the speed or gain of vertical saccades (Pinkhardt et al., 2008). Although we did not detect differences in the speed of saccades with respect to disease duration, this probably reflects intersubject variability, and in those patients in whom we made serial measurements, progressive saccadic slowing was evident (Hardwick et al., 2009).

These results may be interpreted with reference to the simple scheme shown in Figure 1A. First, the riMLF contains excitatory burst neurons for vertical saccades (Horn and Buttner-Ennever, 1998) and bilateral chemical lesions abolish vertical saccades and torsional quick phases of nystagmus (Suzuki et al., 1995). Second, the INC contributes to vertical gaze holding; inactivation of this structure causes a restricted range of vertical movement without inducing slowing of saccades (Helmchen et al., 1998). Involvement of other structures concerned with the generation of vertical saccades, such as the nucleus of the posterior commissure (Moschovakis et al., 1996), may also contribute to the clinical signs, but are less well understood. Experimental lesions of the superior colliculus may cause some slowing of all saccades, but the main effect is an enduring increase in reaction time, which is not as prominent in PSP as it is in other parkinsonian disorders such as cortical-basal ganglionic degeneration. Thus, it appears that the two defects of restricted range and slowing of vertical saccades in PSP could be attributed to involvement of the INC and riMLF, respectively. Relatively greater involvement of one or the other might cause a more pronounced deficit of saccadic range of movement or slowing. How independent these two defects are in each patient with PSP could be investigated by comparing the speed of saccades of similar size made from different starting positions. Our data indicate that vertical saccade speed is affected by the gaze field in which it is made, suggesting an interaction between INC and riMLF.

Why do the results of our large retrospective study appear to conflict with prior reports that emphasize predominant downgaze palsy in PSP (Williams et al., 2008)? Both downgaze and upgaze palsy occurred in the nine originally described patients (Steele et al., 1964). Furthermore, downgaze palsy is not required for diagnosing PSP by NINDS/SPSP criteria (Litvan et al., 1996). However, two explanations seem possible to account for the misconception that downgaze is more affected. First, since many elderly healthy subjects have limited range of upgaze (so-called "Blickerschwernis") but not downgaze (Clark and Isenberg, 2001; Oguro et al., 2004), clinicians may find it more diagnostically certain when a patient, who is being evaluated for a parkinsonian disorder, has difficulty voluntarily looking down. Second, PSP patients with predominant downgaze palsy may be more visually disabled, since most daily activities involving eye-hand coordination take place in the lower field of gaze. We suggest that more important than limitation of gaze is the finding that vertical saccades, both up and down, are slower in PSP patients than in normal subjects (Figure 2), as well as in other parkinsonian disorders. Thus, neurologists should routinely test a number of saccades by asking patients to look, on command, between two points separated in the vertical and horizontal planes. Application of this simple bedside test will help to secure a correct diagnosis (Leigh and Riley, 2000).

\section{FIXATION}

\section{BEHAVIORAL PROPERTIES OF EYE MOVEMENTS DURING ATTEMPTED FIXATION}

When normal subjects attempt to fix their eyes upon a stationary visual target, continuous small movements occur, consisting of microtremor, small drifts, and microsaccades (Martinez-Conde et al., 2004). Microtremor is thought to be too small to compromise vision, and eye drifts are only problematic if they cause excessive slip of retinal images, such as in pathological forms of nystagmus. Microsaccades are now considered important for preventing visual adaptation (fading) of peripheral retinal images (Martinez-Conde et al., 2006, 2009; Troncoso et al., 2008).

In PSP, the prominent movements during attempted steady fixation are saccadic intrusions (Troost and Daroff, 1977), mainly to-and-fro SWJ (see Figure 5). SWJ also occur in normal subjects (Abadi and Gowen, 2004), however, and current evidence suggests that SWJ and microsaccades constitute points on a continuum (Gowen et al., 2007). In PSP, saccades occurring during attempted fixation are not only more frequent and larger than in normal subjects, but they also lack a vertical component (Otero-Millan et al., 2009).

\section{NEURAL SUBSTRATE FOR IMPAIRED FIXATION IN PSP}

Behavioral evidence from human studies supports a common neural mechanism for the generation of saccades and microsaccades (Rolfs et al., 2006; Gowen et al., 2007; Otero-Millan et al., 2008). Thus, there is evidence for dynamic interaction of microsaccades and larger saccades made to a target. Burst neurons in the PPRF discharge for both saccades and microsaccades (Van Gisbergen et al., 1981). Furthermore, neurons in the rostral pole of the superior colliculus, which is known to be important for triggering saccades, are also active for microsaccades (Hafed et al., 2009). Omnipause neurons that stop discharging during saccades also stop during microsaccades (Brien et al., 2009).

Attention reportedly modulates both saccadic intrusions and microsaccades. Why are SWJ larger and more frequent in PSP? One possibility is that SWJ represent an adaptive response to prevent the increased risks of visual fading consequent on voluntary gaze palsy (Martinez-Conde et al., 2006; Troncoso et al., 2008; Otero-Millan et al., 2009). Second, SWJ appear to speed up vertical saccades when they occur synchronously, and might therefore be an adaptation to enhance vertical saccades (Garbutt et al., 2004). Third, the frequent SWJ in PSP may reflect involvement of the cerebellum and its output through the superior cerebellar peduncle (Kanazawa et al., 2009; Dickson et al., 2010); other disorders affecting the cerebellum, such as Friedreich's ataxia show prominent saccadic intrusions (Fahey et al., 2008). Fourth, SWJ in PSP may be due to an enlargement of fixation saccades due to impaired inhibition of the superior colliculus by the substantia nigra pars reticulata; the second (return) saccade might then be triggered by a correcting mechanism that is also present in healthy subjects (Otero-Millan et al., 2009). 

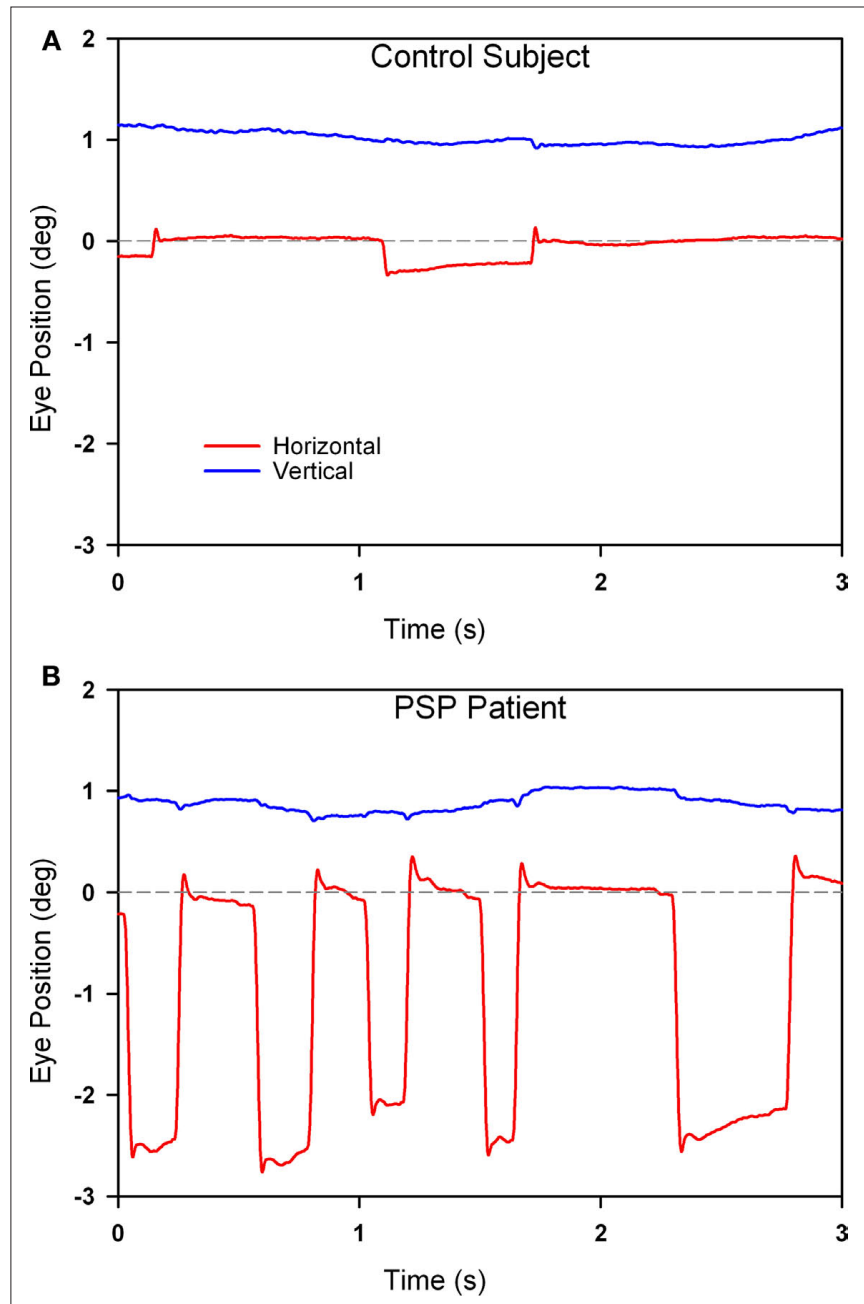

FIGURE 5 | Comparison of fixation behavior in a normal elderly subject (A) and in a patient with PSP (B). Both show saccadic intrusions (squarewave jerks), but they are larger and more frequent in the record from the PSP patient. The gray dashed line corresponds to the desired horizontal position of fixation. The vertical channel has been offset in both records to aid clarity. Positive values indicate rightward and upward movements.

\section{VESTIBULO-OCULAR REFLEXES BEHAVIORAL PROPERTIES OF THE VORS}

The angular and linear vestibulo-ocular reflexes (VORs) are important for clear vision during locomotion. The angular VOR generates eye movements at short-latency $(<15 \mathrm{~ms})$ to compensate for rotational head perturbations (Maas et al., 1989). The angular VOR depends on the semicircular canals of the vestibular labyrinth, which act as angular accelerometers (Leigh and Zee, 2006). During near viewing, since the eyes lie anterior to the axis of head rotation, larger eye rotations are required to hold the eye on target - by as much as $30 \%$ if the target is very near (Viirre et al., 1986). The translational or linear VOR compensates for linear head movements by generating eye movements that are highly dependent on the subject's viewing distance (Liao et al., 2008b). The linear VOR depends on the otolithic organs of the vestibular labyrinth, which sense linear accelerations including gravity (Leigh and Zee, 2006).
During far viewing, geometry dictates that no eye movements at all are necessary to hold images steady on the retina during head translations. However, during viewing of a near target, large eye movements may be necessary to keep the subject's foveal line of sight pointed at a target (see inset on upper panel of Figure 6). Thus, the modulation of the linear VOR by viewing distance is much greater than for the angular VOR. Another important behavioral difference is that whereas the angular VOR usually generates eye movements that hold the line of sight on the target (i.e., the eye movements compensate for head rotations - even when viewing optical infinity), the linear VOR does not (Liao et al., 2008b). These important differences are demonstrated in Figure 6. Studies suggest that the eye movements generated by the linear VOR during viewing of a near target are more suitable for minimizing relative motion between the near target and the distant background (Liao et al., 2008b). This strategy may have evolved to optimize motion parallax, which is used to determine the relative distances of objects as the subject walks through the environment.

In PSP, the angular VOR is relatively preserved until late stages of the course of the disease (Figure 6G; Das and Leigh, 2000). However, the linear VOR is markedly impaired, concordant with the impaired inability of PSP patients to converge their eyes and look at a near target (Figures 6C,D; Liao et al., 2008a). These findings are interpreted further when we consider the possible implications of abnormal eye movements for the pathogenesis of this condition.

\section{NEURAL SUBSTRATE FOR IMPAIRED VESTIBULAR REFLEXES IN PSP}

The brunt of the early pathology in PSP falls on the midbrain (Figure 1D), and this may interfere with the ability to generate convergence, and thereby hinder the ability to appropriately set the linear VOR behavior during near viewing. However, an inability to converge may not be the primary deficit interfering with vestibular reflexes, since viewing distance seems more important than vergence angle in normal subjects' linear VOR performance (Liao et al., 2008b). Furthermore, vergence may be preserved in patients with cerebellar disorders, although they cannot modulate the linear VOR for near viewing (Liao et al., 2008c). This point is developed further in the final section. In addition, the vestibular nuclei show loss of neurons at autopsy in PSP (Steele et al., 1964; Figure 1D), and impairment of central otolithic pathways could contribute to the abnormal linear VOR. In support of this view, vestibular-evoked myogenic potentials (VEMPs), which consist of inhibitory potentials induced in the sternocleidomastoid muscle with loud sounds that stimulate the saccule (Rosengren et al., 2010), are impaired in PSP (Liao et al., 2008a). In fact, one might expect increased VEMPs in PSP patients, as they show increased muscular tension in the sternocleidomastoid muscles as a component of neck rigidity (Colebatch et al., 1994). The saccular and utricular central projections are quite distinct, with the latter projecting mostly to the medial vestibular nuclei and the nodulus and flocculus, and the former to the lateral vestibular nuclei and to the nodulus and uvula (Newlands et al., 2003). While the utricular pathways are thought to be involved in the horizontal linear VOR and vestibulo-ocular motor learning functions, the saccular pathways are considered a component of the vestibulospinal system and might be more involved with the vertical linear VOR. A hypothetical preferential involvement of the central saccular connections in PSP might 


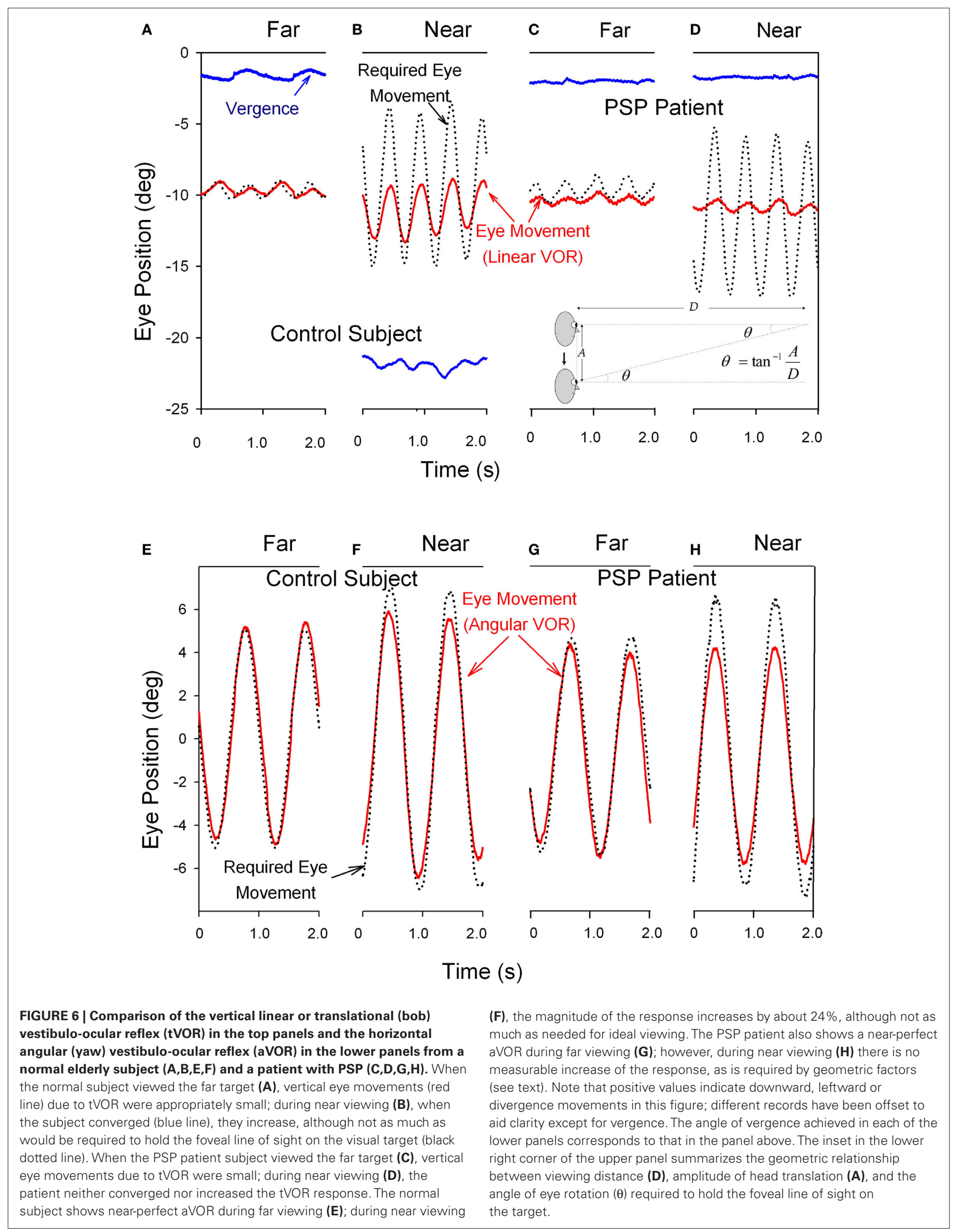


explain some of the clinical findings, such as falling. Interestingly, the nuchocephalic reflex is also impaired in PSP (Jenkyn et al., 1975), and electromyographic responses of the sternocleidomastoid and other muscles to vertical free fall have been shown to be diminished in PSP (Bisdorff et al., 1999).

Additional mechanisms contribute to postural instability in PSP. For example, PSP patients often show head turns opposite to the direction of intended gait (Murdin and Bronstein, 2009). This apparent functional overactivity of the vestibulo-collic reflexes seems mainly due to loss of rapid, resetting head movements, which could be attributed to involvement of the brainstem reticular nuclei.

\section{SMOOTH-TRACKING EYE MOVEMENTS BEHAVIORAL PROPERTIES OF SMOOTH TRACKING}

Motion of images across the retina (retinal slip) serves as the primary stimulus to a range of smooth ocular tracking, including the ocular following response (OFR), optokinetic nystagmus, and smooth pursuit (Table 1; Miles, 1998). The OFR is a pre-attentive, short-latency visual tracking mechanism that can be induced by sudden motion of a sinusoidal grating on a computer screen (in our laboratory, subtending $37.5^{\circ}$ high $\times 50^{\circ}$ wide; Gellman et al., 1990; Sheliga et al., 2005; Joshi et al., 2009). The OFR can even be tested in PSP patients, who cannot focus their visual attention (or fovea) on the stimulus. Typically, OFR are small, and variable between subjects, but show consistent dependence on the direction and spatial frequency of the stimulus (Gellman et al., 1990; Sheliga et al., 2005). The current consensus is that the OFR represents an early, low-level response of the visual system to a moving stimulus (Sheliga et al., 2005; Joshi et al., 2009). The OFR is preserved in patients with PSP (Figure 7C), and shows a similar dependence on the spatial frequency of the stimulus to that shown by normal subjects (Joshi et al., 2010). One difference from control subjects is that responses occur at an increased latency in PSP patients (Figures 7C,D).

Optokinetic nystagmus is a response to sustained self-rotation, such as occurs during locomotion, when vestibular eye movements are progressively less able to stabilize images on the retina. In the laboratory, optokinetic responses are conventionally tested as a large visual surround rotates about the subject for up to a minute,
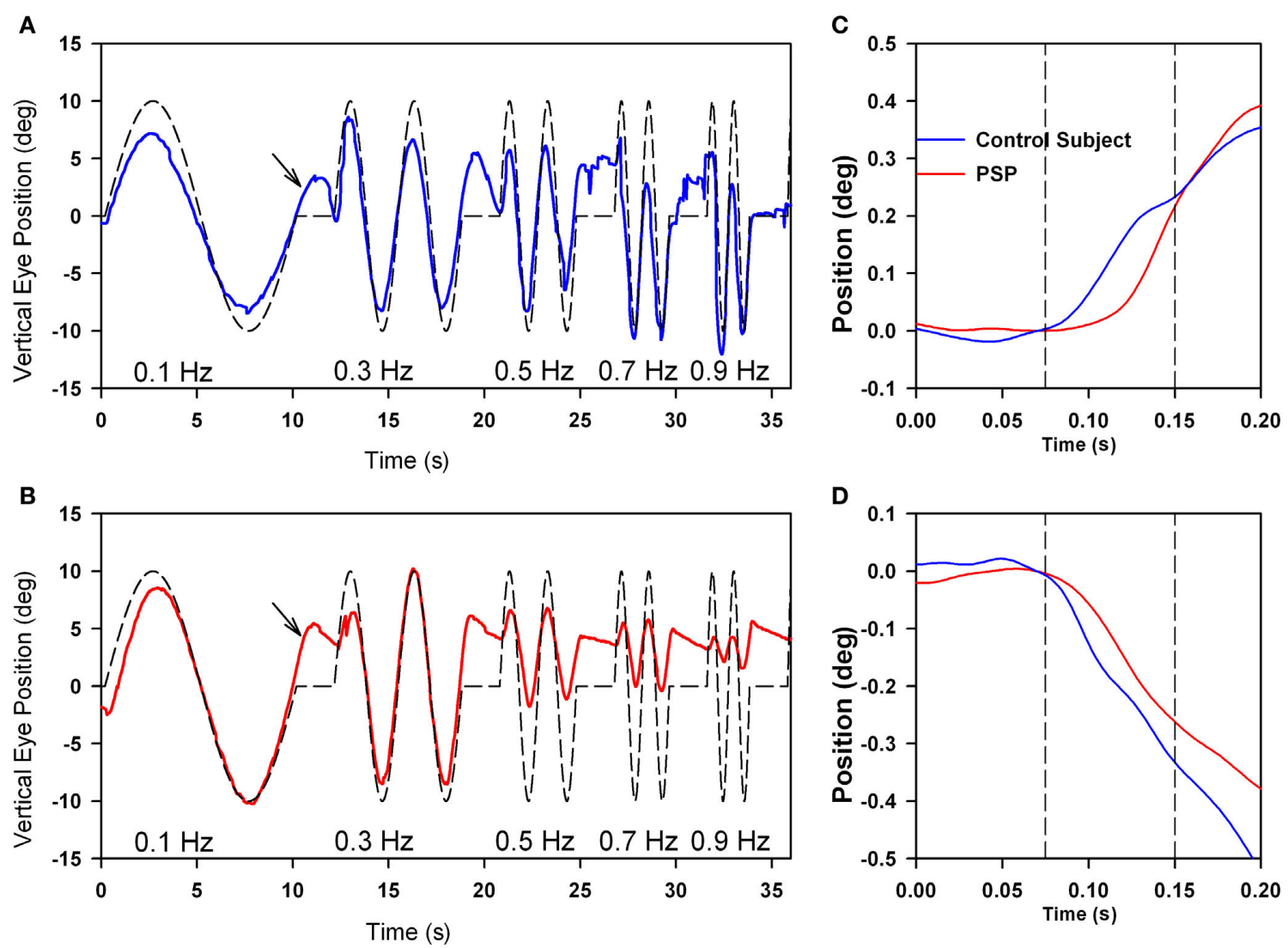

FIGURE 7 | Comparison of vertical smooth pursuit $(A, B)$ and ocular following responses $(\mathrm{C}, \mathrm{D})$ of a normal subject and a PSP patient. Both sets of responses were evoked as subjects viewed vertically-moving sine-wave gratings on a monitor subtending $50^{\circ} \times 37.5^{\circ}$. For pursuit, the stimulus was sinusoidal motion of a 0.27 cycles per degree grating over the range of temporal frequencies shown. For OFR, the stimulus was ramp motion for $200 \mathrm{~ms}$ of a 0.17 cycles per degree grating. At lower frequencies of motion, both the normal subject (A) and the PSP patient (B) showed smooth tracking with some predictive properties (arrows); at high frequencies, the PSP (B) showed substantial decrease in the size of the pursuit movements compared with the control subject. Both upward (C) and downward (D) grating motion induced similar-sized OFR from the control subject (blue line) and PSP patient (red line), although the latency to onset was larger in the patient. See Joshi et al. (2010) for details. 
which induces a strong percept of self-rotation (circularvection). Optokinetic responses induced with a large moving visual display in PSP are reduced compared with control subjects (Garbutt et al., 2004).

Smooth pursuit evolved with the fovea, making it possible to track small targets that move across the stationary background something that the ocular following and optokinetic mechanisms cannot do (Miles, 1998). Smooth pursuit tracking depends on decoding visual motion, selecting a target of interest and keeping the image of the target on or near the fovea. Since eye movements themselves cause motion of images of stationary objects on large portions of the retina, an essential component of smooth pursuit is that attention be paid to the moving target relative to the background. Another important property of smooth pursuit is an ability to track almost perfectly targets that are moving with predictable waveforms, such as sine waves (Barnes, 2008); such motion is common in the real world, for example, the swaying of the branch of a tree. Since the latency for smooth pursuit initiation is over $100 \mathrm{~ms}$, perfect tracking implies that the brain must use a prediction mechanism to achieve tracking without phase shift between the eye and target.

Smooth pursuit tracking in PSP is limited, in part, because the patient may not be able to foveate a small visual target (such as a laser spot) with a saccade. One strategy to cope with this deficit is to present large moving stimuli, such as sine-wave gratings (Seemungal et al., 2003; Joshi et al., 2010); the advantage of this extended stimulus for patients with PSP who cannot make accurate corrective saccades (to bring the image of the target into the fovea) is that some part of its image always occupies the foveal region. Thus, even if the fovea falls behind the motion of one component in the grating, and a foveating saccade cannot be generated, PSP patients can still track the motion of the next stripe in the grating. Using such a strategy, we found that patients were able to smoothly track lower-frequency sinusoidal motion as well as control subjects, and even showed some preservation of the predictive mechanism for pursuit (Figure 7). However, at higher frequencies of stimulus motion, smooth tracking declines substantially in PSP patients compared with control subjects.

\section{NEURAL SUBSTRATE FOR IMPAIRED SMOOTH TRACKING IN PSP}

Anatomical and physiological studies in macaque, and clinical studies in humans, have identified a network of cortical regions and their brainstem projections that contribute to OFR, optokinetic responses, and smooth pursuit (Leigh and Zee, 2006). In humans, cerebral cortex, at the junction of occipital and temporal lobes, is important for computing the speed and direction of moving visual stimuli (Figure 1C). This occipital-temporal region contains the homologs of macaque middle temporal (MT) visual area (Annese et al., 2005), which is important for estimating the speed and direction of moving visual stimuli, and the adjacent medial superior temporal (MST) visual area, which encodes both visual and eye motion signals. The MST visual area has been shown to contribute to both smooth pursuit and OFR (Takemura and Kawano, 2006). Experimental lesions of the MT/MST region in macaque abolish all forms of ocular tracking (Dürsteler and Wurtz, 1988; Takemura et al., 2007). Similarly, lesions affecting this region of occipital-temporal cortex impair visual tracking, including the onset and maintenance of smooth pursuit (Sharpe, 2008). However, tau pathology in PSP largely spares this posterior cortical region (Williams and Lees, 2009). The frontal eye field (FEF), which is affected by tau pathology in PSP, is also important for smooth visual tracking, especially its initiation (MacAvoy et al., 1991; Nuding et al., 2008).

Both MT/MST and FEF project to pontine nuclei via the cerebral peduncles, which are spared in PSP (Figure 1D). The MT/MST projection, which seems more important for the OFR and maintenance of pursuit, synapses in the dorsolateral pontine nucleus (DLPN). The FEF projection, which seems more important for initiation of pursuit, synapses in nucleus reticularis tegmenti pontis (NRTP; Mustari et al., 2009). Both DLPN and NRTP are affected by tau pathology in PSP (Malessa et al., 1994; Joshi et al., 2010), as are the paraflocculus and dorsal vermis of the cerebellum to which they project (Kanazawa et al., 2009). Furthermore, the superior cerebellar peduncle is often severely affected in PSP (Dickson et al., 2010). Thus, on one hand, OFR may be relatively preserved in PSP because it depends on the relatively spared MT/MST-cerebral peduncle pathway and possesses pre-attentive, low-level properties. On the other hand, smooth pursuit may be relatively impaired in PSP because it depends on neural systems involved in attention and prediction, including the parietal and frontal lobes, which are affected by tau pathology. The increased latency of OFR and frequency dependency of pursuit in PSP (Figure 7) may both reflect involvement of pontine nuclei and the cerebellar circuits to which they project. Finally, since the midbrain is heavily affected in PSP (Figure 1D), an accessory optic system, which is well studied in macaque (Cohen et al., 1992; Inoue et al., 2000), seems unlikely to contribute substantially to smooth ocular tracking in humans.

\section{VERGENCE}

\section{BEHAVIORAL PROPERTIES OF VERGENCE}

Clinically, vergence is usually tested by smoothly moving the examiner's handheld visual target (or patient's finger) toward the patient's nose. This tests both accommodative and fusional smooth vergence (Leigh and Zee, 2006). However, during natural visual search, we rapidly shift our point of fixation between features of our world that lie in both different directions and at different distances; this requires combined saccade-vergence movements (Collewijn et al., 1995). An especially common combination of eye movements occurs when we repeatedly switch our point of fixation from an object in our hands to the distant environment. This behavior calls for downward saccades with convergence and upward saccades with divergence, along with any required horizontal saccadic gaze shifts (Kumar et al., 2004).

Clinical studies indicate that vergence is affected early in the course of PSP, thereby accounting for the presenting complaint of horizontal diplopia in some patients (Hardwick et al., 2009). Few studies have measured vergence combined with vertical saccades, such as occurs when attention is switched between a handheld object and a distant target, but we have found that such combined vergence-saccade movements are smaller and slower in PSP patients compared with control subjects (Kitthaweesin et al., 2002). Figure 8 shows saccade-vergence behavior when far and near targets are both aligned on the left eye (Müller paradigm), in a normal subject (A) and in a patient with early PSP (B), who was still able to generate 


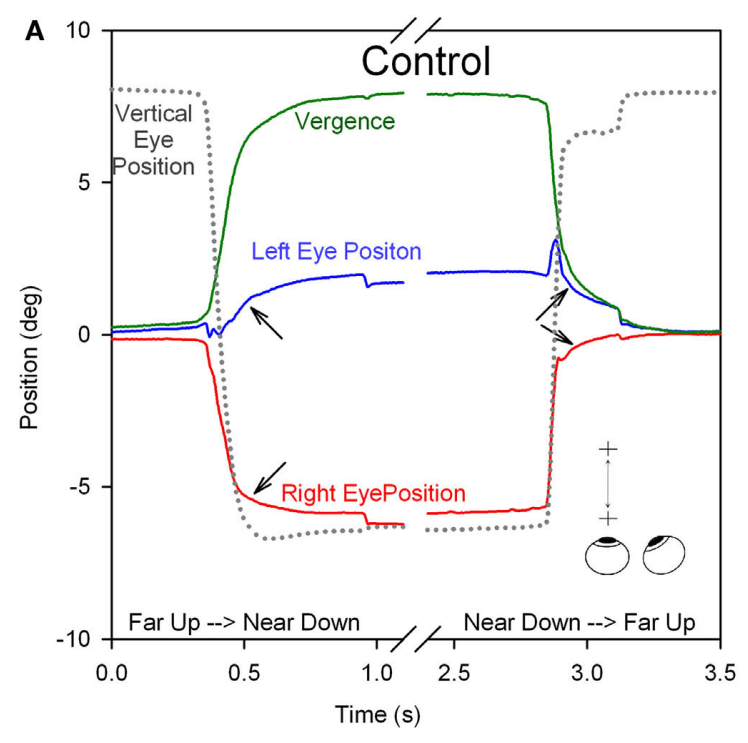

FIGURE 8 | Comparison of combined saccade-vergence responses as a control subject (A) or a patient with early PSP (B) attempted to make shifts of the point of fixation between two visual targets aligned on the left eye (Müller paradigm), one located at far and one at near [see inset in (A)]; the far target was higher than the near target, requiring an associated vertical saccade. The normal subject uses disjunctive saccades (right movement bigger than left) followed by a vergence movement (arrows)

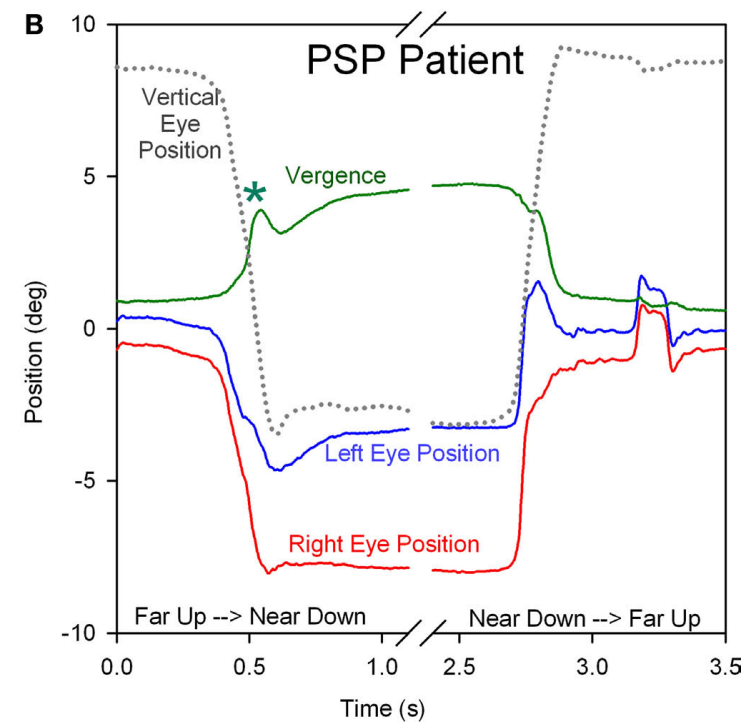

for shifts of the point of fixation in both directions. The PSP patient could not generate an adequate vergence movement (compare with control subject; asterisk signifies a superimposed blink). Furthermore, the horizontal saccadic components were more similar in size (less disjunctive than the control). The associated vertical saccade is also slower in the PSP patient. Thus, the complete synkinesis of saccades and vergence is affected in this PSP patient. some convergence movements (although at a later recording session, they were absent). In Figure 8A, note how initially the normal subject generates disjunctive (unequal) saccades, so that while the right eye makes a large movement to the left, the left eye hardly moves (thereby converging the eyes with a saccade); a smooth convergence movement follows (arrows). The subsequent divergence is also achieved first by disjunctive saccades followed by a smooth vergence movement of both eyes (arrows). In Figure 8B, the change in vergence achieved by the PSP patient is smaller than by the normal subject (although a similar-sized movement was required in both cases). Note that both the disjunctive saccadic and smooth vergence components were reduced in amplitude compared with the control subject. The vertical saccades accompanying the shift of fixation are also smaller and slower in the PSP patient than the control subject. Thus, it appears probable that the entire synkinesis of saccades and vergence is affected in PSP.

\section{NEURAL SUBSTRATE FOR IMPAIRED VERGENCE IN PSP}

The midbrain houses neurons that project to ocular motoneurons and are important for the control of vergence. These neurons lie in the mesencephalic reticular formation, 1-2 mm dorsal and dorsolateral to the oculomotor nucleus, a region referred to as the supraoculomotor area (Mays, 1984; Judge and Cumming, 1986; Zhang et al., 1991). Neurons variously encoding vergence angle, the speed of vergence movements, and both have been described (Mays et al., 1986). Some of these neurons also respond to changes of accommodation, but most seem predominantly concerned with vergence (Zhang et al., 1992). This area of the midbrain is heavily affected by tau pathology in PSP (Figure 1D), accounting for defects of vergence eye movements (as well as attendant vertical saccades). It seems likely that any residual vergence ability during rapid shifts of the fixation point may be mainly due to disjunctive horizontal saccades, although these movements also are impaired in PSP (Figure 8B). As noted above, the defect of convergence in PSP coexists with an inability to modulate the linear VOR appropriately for viewing of a near target. Evidence linking these two deficits to other findings in PSP will be discussed in the final section, where we attempt to develop a new hypothesis to account for the pathogenesis of this disorder.

\section{DISTURBANCES OF EYE MOVEMENTS IN PSP VARIANTS}

It is now recognized that the clinical presentation of PSP is variable (Williams and Lees, 2009). One syndrome overlapping with PSP is pure akinesia (PA), defined in 1974, and developed in a series of subsequent articles, by Imai and Narabayashi (1974), Mizusawa et al. (1993), and Imai (1996). The core of this syndrome consists of profound disturbances in the three clinical domains of speech, handwriting and gait, in the absence of gaze palsy, tremor, limb rigidity or akinesia, dementia, and levodopa responsiveness. Based on longitudinal studies, we reported that PA patients may develop slow and small saccades as their disease progresses (Riley et al., 1994). We suggested that clinical recognition of PA might permit identification of PSP patients before they develop supranuclear gaze palsy. The two first patients of that report subsequently underwent autopsy examination, and we summarize their clinical and pathological findings here.

The initial symptom of Patient 1 was micrographia at the age of 59 , followed years later by stuttering of speech and start-hesitation on walking. He took $1750 \mathrm{mg}$ of levodopa daily for 6 years without benefit, fluctuations or dyskinesia. His later course featured severe freezing of gait, festinating speech, dysarthria, eyelid freezing 
("apraxia of eyelid opening"), and blepharospasm. We measured his eye movements, 14 years after onset of PA, and found slow and hypometric vertical and horizontal saccades (Figures 9A,B) and intermittent saccadic intrusions. The angular VOR was normal. During the last 4 years of his life, slowing of vertical saccades and restriction of vertical gaze were clinically evident. He also developed flexion contractures of his hands and feet. He became unable to sit without support. He died at age 78 after nearly 20 years of illness. His brain weighed $1450 \mathrm{~g}$ but appeared moderately atrophic. Microscopically, there was severe neuronal loss and gliosis involving the globus pallidus, substantia nigra and subthalamic nuclei. Surviving neurons in these structures contained globose NFTs (Figure 9C), as did several pontine nuclei. These intracellular inclusions were highlighted with antibodies to tau protein (Figure 9D), which also confirmed the absence of neocortical neurofibrillary degeneration. Lewy bodies were not identified by H\&E staining or ubiquitin immunohistochemistry.
Patient 2 began noting festination of speech and shuffling of gait at the age of 65. Later his handwriting became very small. Levodopa at a dose of up to $1500 \mathrm{mg} /$ day produced no benefit. On examination 7 years after onset, he had profound impairment of speech with extreme stuttering, festination, and whispering hypophonia. $\mathrm{He}$ showed spontaneous blepharospasm affecting his left eye. Pursuit movements were saccadic, but only upward gaze was restricted in range. Vertical saccades appeared to be of normal velocity. Muscle tone was normal in the neck and limbs. Gait was very slow with very short steps and frequent freezing. He showed no reaction to postural stability testing. Because of glaucoma, we recorded his eye movements using an infrared reflection technique, 8 years into his illness. There were numerous saccadic intrusions. He had difficulty initiating saccades, but horizontal saccades were normal. Vertical saccades were slow and hypometric. Pursuit movements were saccadic, but the range was normal. The angular VOR was normal, both horizontally and vertically. Convergence was lost. In

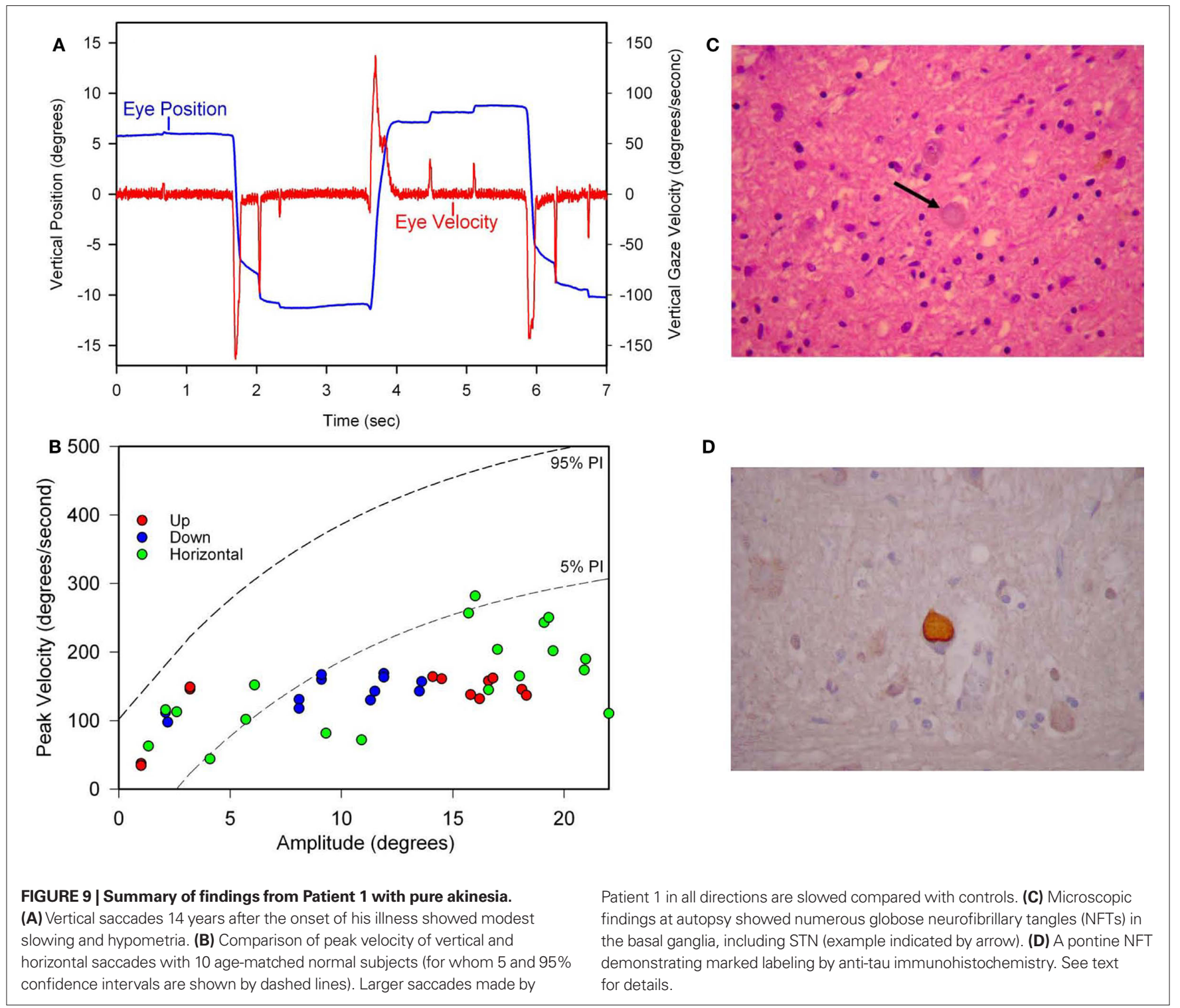


subsequent years his speech became progressively unintelligible, he displayed severe flexion at the waist when standing, and his walking virtually ceased because of severe freezing. He developed eyelid freezing and severe bilateral blepharospasm that responded to repeated botulinum toxin injections. Ten years after onset, he showed delayed initiation of saccades, especially vertically. His later course also featured neck rigidity and dysphagia. He became lethargic 12 years into his illness and was found to have a large left parietotemporal tumor. He and his wife declined surgery, and he died shortly afterward at the age of 77, 12 years after onset. Until the end of his life, he showed only a moderate restriction of upward gaze, and was able to generate clinically normal downward saccades. His brain weighed $1420 \mathrm{~g}$. Microscopically, there was severe degeneration and gliosis of the globus pallidus, substantia nigra and part of the putamen. Tau immunostaining revealed numerous large, globose NFTs in subthalamic nuclei and hypothalamus. There were occasional NFTs among the few surviving substantia nigra neurons. There were occasional, poorly formed globose NFTs in cortical neurons, but no senile plaques or Lewy bodies. There was a soft, friable $4.5 \mathrm{~cm}$ mass in the left inferior frontal and superior temporal lobes with associated edema; sections of the tumor were consistent with a high-grade astrocytoma.

Our clinical and pathologic experience with PA is similar to that of other investigators. Thus, in PA Imai and Narabayashi described a restricted form of PSP, initially without gaze palsy, and with a more protracted course and benign prognosis (Imai, 1996). None of the clinical findings in PA are inconsistent with PSP, distinguishing PA from other PSP-overlap syndromes, in which patients present with features typical of other degenerative disorders such as idiopathic Parkinson's disease, cortical-basal ganglionic degeneration, or progressive non-fluent aphasia (Williams and Lees, 2009). What information does measurement of eye movements bring to these other overlap syndromes? Our experience, and that of other investigators, is that patients with idiopathic Parkinson's disease, cortical-basal ganglionic degeneration or multiple system atrophy do not show slow vertical saccades until the advanced stages of their disease course (White et al., 1983; Rottach et al., 1996; Bhidayasiri et al., 2001), if ever. Based on our studies of a small number of PSP patients who presented with a Parkinson's diseaselike syndrome, we agree with a prior report that such patients show slowing and hypometria of vertical saccades, similar to typical PSP (Richardson's syndrome; Pinkhardt et al., 2008). Thus, measurements of eye movements are consistent with the view, based on clinicopathological correlation, that there is some overlap of PSP variants. What factors could determine the selective vulnerability of populations of neurons in theses different forms of tauopathy? Since the disturbances of gaze in PSP point to specific brainstem circuits, it is possible to approach the question from a different viewpoint, which we attempt next.

\section{DISCUSSION: A SYNTHESIS OF THE GAZE DISORDER IN PSP THAT LEADS TO A NEW HYPOTHESIS FOR ITS PATHOGENESIS}

One may ask whether the constellation of eye movement disturbances that we summarize in this review offer any insights into the pathogenesis of PSP. One clue to their interpretation seems to be the consistent feature of falls early in the course of the disorder. Bipedal upright locomotion is a later occurrence in evolution, and most primates other than humans do not habitually move in an erect posture through their environment with their upper limbs free to scavenge food or use weapons (Niemitz, 2010). Shifts of the point of visual fixation between the activities of the hands and the approaching horizon (eye-hand coordination) require combined saccade-vergence movements, such as downward saccades with convergence, which are severely impaired in PSP.

Failure of otolith-ocular and otolith-spinal reflexes, possibly involving the saccular projections to vestibular nuclei, cerebellum, and frontal lobes (structures that are all involved in PSP), with preservation of canal-vestibular reflexes, implies involvement of a relatively new set of behaviors that were required during adaption to upright locomotion. Involvement of these pathways might explain failure of equilibrium in upright posture, with resultant frequent falls. We propose that PSP may owe its distinctive set of disturbances of eye movements and balance to selective involvement of a recently evolved neural system that deals with erect bipedal locomotion, the main components of which lie in the midbrain. The pedunculopontine nucleus (PPN) and the nucleus cuneiformis have been identified by physiological and fMRI studies as important for human locomotion, especially its initiation (Jahn et al., 2008); these structures are affected in PSP (Warren et al., 2005). The disorder of vertical voluntary gaze predominantly affects vertical saccades and associated vergence (riMLF and adjacent near response neurons), which are called on as humans move forward to gather food or use weapons, while keeping an eye on the horizon. The limitation of gaze may reflect involvement of structures such as INC, which is manifest by abnormalities of the linear VOR, VEMPs, and by retrocollis. The smooth following eye movements that are most affected in PSP are governed by the frontal lobes; more reflexive visual following that depends on posterior cortical areas is preserved. This mirrors the cognitive disturbances associated with PSP, which are primarily frontal lobe deficits. The cerebellum and its output through the superior peduncle are also involved in PSP (Kanazawa et al., 2009; Dickson et al., 2010), and may be responsible for the disturbance of fixational eye movements, in which large paired horizontal saccadic intrusions frequently occur. The cerebellum also makes an important contribution to the generation of the rhythmic nature of locomotion.

PSP is currently classified as a tauopathy that affects the terminal part of axonal neurofilaments. We suggest that the particular distribution of this tau pathology in PSP is defined by a neural system that evolved to promote erect bipedal locomotion and the visual needs consequent on freedom to use the upper limbs for foraging food or readying a weapon aimed at a distant food source. This notion of involvement of a recently evolved neural system is consistent with the pattern of other tauopathies, such corticalbasal ganglionic degeneration, progressive non-fluent aphasia, or Alzheimer disease, which all involve functions characteristic of Homo sapiens such as language, cognition, and the ability to learn complex motor behaviors. When viewed this way, a new set of questions emerges that comparative anatomy, and molecular biology can address. It also leads to a larger question of whether the various forms of neurodegenerative disease, including the range of parkinsonian disorders and diseases affecting memory, praxis, and language, are also represented in neural systems that evolved in recent time to make humans human. 


\section{ACKNOWLEDGMENTS}

We are grateful to Dr. John Steele for reviewing the manuscript and making suggestions for improvement, to Dr. Robert Daroff for his critical comments, and to Drs Michael Devereaux, Alan Lerner, Robert Friedland, Janet Rucker, and Brian Koo for their support of our research efforts. Supported by National Institutes of Health grant R01 EY06717, the Department of Veterans Affairs and the Evenor Armington Fund (to Dr. Leigh);

\section{REFERENCES}

Abadi, R. V., and Gowen, E. (2004). Characteristics of saccadic intrusions. Vision Res. 44, 2675-2690.

Annese, J., Gazzaniga, M. S., and Toga, A. W. (2005). Localization of the human cortical visual area MT based on computer aided histological analysis. Cereb. Cortex 15, 1044-1053.

Barnes, G. R. (2008). Cognitive processes involved in smooth pursuit eye movements. Brain Cogn. 68, 309-326.

Bhidayasiri, R., Riley, D. E., Somers, J. T., Lerner,A. J., Buttner-Ennever, J.A., and Leigh, R. J. (2001). Pathophysiology of slow vertical saccades in progressive supranuclear palsy. Neurology 57, 2070-2077.

Bisdorff, A. R., Bronstein, A., Wolsley, C., Gresty, M. A., Davies, A., and Young, A. (1999). EMG responses to free fall in elderly subjects and akinetic rigid patients. J. Neurol. Neurosurg. Psychiatr. 66, 447-455.

Brien, D. C., Corneil, B. D., Fecteau, J. H., Bell, A. H., and Munoz, D. P. (2009). The behavioral and neurophysiological modulation of microsaccades in monkeys. J. Eye Mov. Res. 3, 1-12.

Clark, R.A., and Demer, J. L. (2002). Effect of aging on human rectus extraocular muscle paths demonstrated by magnetic resonance imaging. Am. J. Ophthalmol. 134, 872-878.

Clark, R.A., and Isenberg, S. J. (2001). The range of ocular movements decreases with aging. J. AAPOS 5, 26-30.

Cohen, B., Reisine, H., Yokota, J. I., and Raphan, T. (1992). The nucleus of the optic tract. Ann. N. Y. Acad. Sci. 656, 277-296.

Colebatch, J. G., Halmagyi, G. M., and Skuse, N. F. (1994). Myogenic potentials generated by a click-evoked vestibulocollic reflex. J. Neurol. Neurosurg. Psychiatr. 57, 190-197.

Collewijn, H., Erkelens, C. J., and Steinman, R. M. (1988). Binocular coordination of human vertical saccadic eye movements. J. Physiol. (Lond.) 404, 183-197.

Collewijn, H., Erkelens, C. J., and Steinman, R. M. (1995). Voluntary binocular gaze-shifts in the plane of regard: dynamics of version and vergence. Vision Res. 35, 3335-3358.
Das, V. E., and Leigh, R. J. (2000). Visual-vestibular interaction in progressive supranuclear palsy. Vision Res. 40, 2077-2081.

Dickson, D. W., Ahmed, Z., Algom, A. A., Tsuboi, Y., and Josephs, K. A. (2010). Neuropathology of variants of progressive supranuclear palsy. Curr.

Dürsteler, M. R., and Wurtz, R. H. (1988). Pursuit and optokinetic deficits following chemical lesions of cortical areas MT and MST. J. Neurophysiol. 60, 940-965.

Fahey, M. C., Cremer, P. D., Aw, S. T., Millist, L., Todd, M. J., White, O. B., Halmagyi, M., Corben, L. A., Collins, V., Churchyard, A. J., Tan, K., Kowal, L., and Delatycki, M. B. (2008). Vestibular, saccadic and fixation abnormalities in genetically confirmed Friedreich ataxia. Brain 131, 1035-1045.

Garbutt, S., Harwood, M. R., Kumar, A N., Han, Y. H., and Leigh, R. J. (2003). Evaluating small eye movements in patients with saccadic palsies. Ann N. Y. Acad. Sci. 1004, 337-346.

Garbutt, S., Matlin, A., Hellmuth, J. Schenk, A. K., Johnson, J. K., Rosen, H., Dean, D., Kramer, J., Neuhaus, J., Miller, B. L., Lisberger, S. G., and Boxer, A. L. (2008). Oculomotor function in frontotemporal lobar degeneration, related disorders and Alzheimer's disease. Brain 131, 1268-1281.

Garbutt, S., Riley, D. E., Kumar, A. N., Han, Y., Harwood, M. R., and Leigh, R. J. (2004). Abnormalities of optokinetic nystagmus in progressive supranuclear palsy. J. Neurol. Neurosurg. Psychiatr. $75,1386-1394$.

Gellman, R. S., Carl, J. R., and Miles, F. A. (1990). Short latency ocular-following responses in man. Vis. Neurosci. 5, 107-122.

Gowen, E., Abadi, R. V., Poliakoff, E., Hansen, P. C., and Miall, R. C. (2007). Modulation of saccadic intrusions by exogenous and endogenous attention. Brain Res. 1141, 154-167.

Hafed, Z. M., Goffart, L., and Krauzlis, R. J. (2009). A neural mechanism for microsaccade generation in the primate superior colliculus. Science 323, 940-943.

Hardwick, A., Rucker, J. C., Cohen, M. L., Friedland, R. P., Gustaw-Rothenberg, Opin. Neurol. 23, 394-400.

the National Center for Research Resources, Cleveland Medical Devices, and the Gift of Nina and Sandy McAfee (to Dr. Riley); Fundación Barrié de la Maza (to Mr. Otero-Millan); the Arizona Biomedical Research Commission (award 07-102), the National Science Foundation (awards 0643306 and 0852636) and the Barrow Neurological Foundation (to Dr. Martinez-Conde); the German Ministry for Education and Research (IFB-LMU to Dr. Michael Strupp).

K., Riley, D. E., and Leigh, R. J. (2009). Evolution of oculomotor and clinical findings in autopsy-proven Richardson syndrome. Neurology 73 2122-2124.

Helmchen, C., Rambold, H., Fuhry, L., and Büttner, U. (1998). Deficits in vertical and torsional eye movements after uni- and bilateral muscimol inactivation of the interstitial nucleus of Cajal of the alert monkey. Exp. Brain Res. 119, 436-452.

Henson, C., Staunton, H., and Brett, F. M (2003). Does ageing have an effect on midbrain premotor nuclei for vertical eye movements? Mov. Disord. 18 , 688-694.

Horn, A. K. (2006). The reticular formation. Prog. Brain Res. 151, 33-79.

Horn, A. K., and Buttner-Ennever, J. A (1998). Premotor neurons for vertical eye movements in the rostral mesencephalon of monkey and human: histologic identification by parvalbumin immunostaining.J. Comp. Neurol.392, 413-427.

Horn, A. K. E., Büttner-Ennever, J. A. Suzuki, Y., and Henn, V. (1997). Histological identification of premotor neurons for horizontal saccades in monkey and man by parvalbumin immunostaining. J. Comp. Neurol. 359 350-363.

Huaman, A. G., and Sharpe, J. A. (1993). Vertical saccades in senescence. Invest. Ophthalmol. Vis. Sci. 34, 2588-2595.

Imai, H. (1996). Clinicophysiological features of akinesia. Eur. Neurol. 36(Suppl. 1), 9-12.

Imai, H., and Narabayashi, H. (1974) Akinesia - concerning 2 cases of pure akinesia. Shinkei Kenkyu Shimpo 18 787-794.

Inoue, Y., Takemura, A., Kawano, K., and Mustari, M. J. (2000). Role of the pretectal nucleus of the optic tract in short-latency ocular following responses in monkeys. Exp. Brain Res. 131, 269-281.

Jahn, K., Deutschlander, A., Stephan, T., Kalla, R., Hufner, K., Wagner, J., Strupp, M., and Brandt, T. (2008). Supraspinal locomotor control in quadrupeds and humans. Prog. Brain Res. 171, 353-362.

Jenkyn, L. R., Walsh, D. B., Walsh, B. T., Culver, C. M., and Reeves, A. G. (1975).
The nuchocephalic reflex. J. Neurol. Neurosurg. Psychiatr. 38, 561-566.

Joshi, A. C., Riley, D. E., Mustari, M. J., Cohen, M. L., and Leigh, R. J. (2010) Selective defects of visual tracking in progressive supranuclear palsy (PSP): implications for mechanisms of motion vision. Vision Res. 50, 761-771.

Joshi, A. C., Thurtell, M. J., Walker, M. F, Serra, A., and Leigh, R. J. (2009). Effect of vergence on human ocular following response (OFR). J. Neurophysiol. 102, 513-522.

Judge, S. J., and Cumming, B. G. (1986) Neurons in the monkey midbrain with activity related to vergence eye movement and accommodation. $J$. Neurophysiol. 55, 915-930.

Kanazawa, M., Shimohata, T., Toyoshima Y., Tada, M., Kakita, A., Morita, T., Ozawa, T., Takahashi, H., and Nishizawa, M. (2009). Cerebellar involvement in progressive supranuclear palsy: a clinicopathological study. Mov. Disord. 24, 1312-1318.

Kato, N., Arai, K., and Hattori, T. (2003). Study of the rostral midbrain atrophy in progressive supranuclear palsy. $J$. Neurol. Sci. 15, 57-60.

Kennard, C., and Leigh, R. J. (2008). Using eye movements as an experimental probe of brain function. Prog. Brain Res. 171, 1-613.

Kitthaweesin, K., Riley, D. E., and Leigh, R. J. (2002). Vergence disorders in progressive supranuclear palsy. Ann. N. Y. Acad. Sci. 956, 504-507.

Kokkoroyannis, T., Scudder, C. A. Balaban, C. D., Highstein, S. M., and Moschovakis, A. K. (1996). Anatomy and physiology of the primate interstitial nucleus of Cajal. 1. Efferent projections. J. Neurophysiol. 75, 725-739.

Kumar, A. N., Han, Y., Dell'Osso, L. F., Durand, D. M., and Leigh, R. J. (2004). Directional asymmetry during combined saccade-vergence movements. J. Neurophysiol. 93, 2797-2808.

Leigh, R. J., and Kennard, C. (2004). Using saccades as a research tool in the clinical neurosciences. Brain 127, 460-477.

Leigh, R. J., and Riley, D. E. (2000). Eye movements in parkinsonism: it's saccadic speed that counts. Neurology 54 , 1018-1019. 
Leigh, R. J., and Zee, D. S. (2006). The Neurology of Eye Movements, 4th Edn, Book/CD-rom. New York: Oxford University Press.

Liao, K., Wagner, J., Joshi, A., Estrovich, I., Walker, M. F., Strupp, M., and Leigh, R. J. (2008a). Why do patients with PSP fall? Evidence for abnormal otolith responses. Neurology 70 , 802-809.

Liao, K., Walker, M. F., Joshi, A., Reschke, M., and Leigh, R. J. (2008b). Vestibuloocular responses to vertical translation in normal human subjects. Exp. Brain Res. 185, 553-562.

Liao, K., Walker, M. F., and Leigh, R. J. (2008c). Abnormal vestibular responses to vertical head motion in cerebellar ataxia. Ann. Neurol. 64, 224-227.

Ling, H., O’Sullivan, S. S., Holton, J. L., Revesz, T., Massey, L. A., Williams, D. R., Paviour, D. C., and Lees, A. J. (2010). Does corticobasal degeneration exist? A clinicopathological reevaluation. Brain 133, 2045-2057.

Litvan, I., Agid, Y., Calne, D., Campbell, G., Dubois, B., Duvoisin, R. C., Goetz, C. G., Golbe, L. I., Grafman, J., Growdon, J. H., Hallett, M., Jankovic, J., Quinn, N. P., Tolosa, E., and Zee, D. S. (1996). Clinical research criteria for the diagnosis of progressive supranuclear palsy (Steele-Richardson-Olszewski syndrome): report of the NINDS-SPSP international workshop. Neurology 47, 1-9.

Maas, E. F., Huebner, W. P., Seidman, S. H., and Leigh, R. J. (1989). Behavior of human horizontal vestibulo-ocular reflex in response to high-acceleration stimuli. Brain Res. 499, 153-156.

MacAvoy, M. G., Gottlieb, J. P., and Bruce, C. J. (1991). Smooth-pursuit eye movement representation in the primate frontal eye field. Cereb. Cortex 1, 95-102.

Malessa, S., Gaymard, B., Rivaud, S., Cervera, P., Hirsch, E., Verny, M., Duyckaerts, C., Agid, Y., and PierrotDeseilligny, C. (1994). Role of pontine nuclei damage in smooth pursuit impairment of progressive supranuclear palsy: a clinical-pathologic study. Neurology 44, 716-721.

Martinez-Conde, S., Macknik, S. L., and Hubel, D. H. (2004). The role of fixational eye movements in visual perception. Nat. Rev. Neurosci. 5, 229-240.

Martinez-Conde, S., Macknik, S. L., Troncoso, X. G., and Dyar, T. A. (2006). Microsaccades counteract visual fading during fixation. Neuron 49, 297-305.

Martinez-Conde, S., Macknik, S. L., Troncoso, X. G., and Hubel, D. H. (2009). Microsaccades: a neurophysiological analysis. Trends Neurosci. 32, 463-475.

Mays, L. E. (1984). Neural control of vergence eye movements: convergence and divergence neurons in midbrain. J. Neurophysiol. 51, 1091-1108.

Mays, L. E., Porter, J. D., Gamlin, P. D., and Tello, C. A. (1986). Neural control of vergence eye movements: neurons encoding vergence velocity. $J$. Neurophysiol. 56, 1007-1021.

Miles, F. A. (1998). The neural processing of 3-D visual information: evidence from eye movements. Eur. J. Neurosci. 10, 811-822.

Mizusawa, H., Mochizuki, A., Ohkoshi, N., Yoshizawa, K., Kanazawa, I., and Imai, H. (1993). Progressive supranuclear palsy presenting with pure akinesia. Adv. Neurol. 60, 618-621.

Moschovakis, A. K., Scudder, C. A., and Highstein, S. M. (1991a). Structure of the primate oculomotor burst generator.I.Medium-lead burst neurons with upward on-directions. J. Neurophysiol. 65, 203-217.

Moschovakis, A. K., Scudder, C. A., Highstein, S. M., and Warren, J. D. (1991b). Structure of the primate oculomotor burst generator. II. Mediumlead burst neurons with downward on-directions. J. Neurophysiol. 65, 218-229.

Moschovakis, A. K., Scudder, C. A., and Highstein, S. M. (1996). The microscopic anatomy and physiology of the mammalian saccadic system. Prog. Neurobiol. 50, 133-254.

Murdin, L., and Bronstein, A. M. (2009). Head deviation in progressive supranuclear palsy: enhanced vestibulo-collic reflex or loss of resetting head movements? J. Neurol. 256, 1143-1145.

Mustari, M. J., Ono, S., and Das, V. E. (2009). Signal processing and distribution in cortical-brainstem pathways for smooth pursuit eye movements. Ann. N. Y. Acad. Sci. 1164, 147-154.

Nachev, P., Kennard, C., and Husain, M. (2008). Functional role of the supplementary and pre-supplementary motor areas. Nat. Rev. Neurosci. 9, 856-869.

Newlands, S. D., Vrabec, J. T., Purcell, I. M., Stewart, C.M.,Zimmerman, B.E., and Perachio, A. A. (2003). Central projections of the saccular and utricular nerves in macaques. J. Comp. Neurol. 466, 31-47.

Niemitz, C. (2010). The evolution of the upright posture and gait-a review and a new synthesis. Naturwissenschaften 97, 241-263.

Nuding, U., Ono, S., Mustari, M.J., Buttner, U., and Glasauer, S. (2008). A theory of the dual pathways for smooth pursuit based on dynamic gain control. J. Neurophysiol. 99, 2798-2808.

Oguro, H., Okada, K., Suyama, N., Yamashita, K., Yamaguchi, S., and Kobayashi, S. (2004). Decline of vertical gaze and convergence with aging. Gerontology 50, 177-181.

Otero-Millan, J., Serra, A., Leigh, R. J., Troncoso, X. G., Macknik, S. L., and Martinez-Conde, S. (2009). Objective characterization of square-wave jerks differentiates progressive supranuclear palsy patients from healthy volunteers. Soc. Neurosci. Abstr. 405.8.

Otero-Millan, J., Troncoso, X. G., Macknik, S. L., Serrano-Pedraza, I., and Martinez-Conde, S. (2008) Saccades and microsaccades during visual fixation, exploration, and search: foundations for a common saccadic generator. J. Vis. 8, 21-18.

Pierrot-Deseilligny, C., Muri, R. M., Ploner, C. J., Gaymard, B., Demeret, S., and Rivaud-Pechoux, S. (2003). Decisional role of the dorsolateral prefrontal cortex in ocular motor behaviour. Brain 126, 1460-1473.

Pierrot-Deseilligny, C., Rivaud, S., Pillon, B., Fournier, E., and Agid, Y. (1989). Lateral visually-guided saccades in progressive supranuclear palsy. Brain 112(Pt 2), 471-487.

Pinkhardt, E. H., Jurgens, R., Becker W., Valdarno, F., Ludolph, A. C., and Kassubek, J. (2008). Differential diagnostic value of eye movement recording in PSP-parkinsonism, Richardson's syndrome, and idiopathic Parkinson's disease. J. Neurol. 255, 1916-1925.

Riley, D. E., Fogt, N., and Leigh, R. J. (1994). The syndrome of 'pure akinesia' and its relationship to progressive supranuclear palsy. Neurology 44 1025-1029.

Rivaud-Pechoux, S., Vidailhet, M., Gallouedec, G., Litvan, I., Gaymard, B., and Pierrot-Deseilligny, C. (2000). Longitudinal ocular motor study in corticobasal degeneration and progressive supranuclear palsy. Neurology 54, 1029-1032.

Robinson, D. A. (1963). A method of measuring eye movement using a scleral search coil in a magnetic field. IEEE Trans. Biomed. Eng. 10, 137-145.

Rolfs, M., Laubrock, J., and Kliegl, R. (2006). Shortening and prolongation of saccade latencies following microsaccades. Exp. Brain Res. 169 369-376.

Rosengren, S. M., Welgampola, M. S., and Colebatch, J. G. (2010). Vestibular evoked myogenic potentials: past, present and future. Clin. Neurophysiol. 121, 636-651.

Rottach, K. G., Riley, D. E., DiScenna, A. O., Zivotofsky, A. Z., and Leigh, R. J. (1996). Dynamic properties of horizontal and vertical eye movements in parkinsonian syndromes. Ann. Neurol. 39, 368-377.

Seemungal, B. M., Faldon, M., Revesz, T., Lees, A. J., Zee, D. S., and Bronstein, A. M. (2003). Influence of target size on vertical gaze palsy in a pathologically proven case of progressive supranuclear palsy. Mov. Disord. 18, 818-822.

Serra, A., Liao, K., Matta, M., and Leigh, R. J. (2008). Diagnosing disconjugate eye movements: phase-plane analysis of horizontal saccades. Neurology 71, 1167-1175.

Sharpe, J. A. (2008). Neurophysiology and neuroanatomy of smooth pursuit: lesion studies. Brain Cogn. 68, 241-254.

Sheliga, B. M., Chen, K. J., FitzGibbon, E. J., and Miles, F. A. (2005). Initial ocular following in humans: a response to first-order motion energy. Vision Res. 45, 3307-3321.

Steele, J. C., Richardson, J. C., and Olszewski, J. (1964). Progressive supranuclear palsy. A heterogeneous degeneration involving the brain stem, basal ganglia and cerebellum with vertical gaze and pseudobulbar palsy, nuchal dystonia and dementia. Arch. Neurol. 10, 333-359.

Suzuki, Y., Büttner-Ennever, J. A., Straumann, D., Hepp, K., Hess, B. J. M., and Henn, V. (1995). Deficits in torsional and vertical rapid eye movements and shift of Listing's plane after uni- and bilateral lesions of the rostral interstitial nucleus of the medial longitudinal fasciculus. Exp. Brain Res. 106, 215-232.

Takemura, A., and Kawano, K. (2006). Neuronal responses in MST reflect the post-saccadic enhancement of shortlatency ocular following responses. Exp. Brain Res. 173, 174-179.

Takemura, A., Murata, Y., Kawano, K., and Miles, F. A. (2007). Deficits in shortlatency tracking eye movements after chemical lesions in monkey cortical areas MT and MST. J. Neurosci. 27, 529-541.

Troncoso, X. G., Macknik, S. L., and Martinez-Conde, S. (2008). Microsaccades counteract perceptual filling-in. J. Vis. 8, 15-19.

Troost, B. T., and Daroff, R. B. (1977) The ocular motor defects in progressive supranuclear palsy. Ann. Neurol. 2, 397-403.

Van Gisbergen, J. A. M., Robinson, D. A., and Gielen, S. (1981). A quantitative analysis of the generation of saccadic eye movements by burst neurons. $J$. Neurophysiol. 45, 417-442.

Viirre, E., Tweed, D., Milner, K., and Vilis, T. (1986). A reexamination of the gain of the vestibuloocular reflex. J. Neurophysiol. 56, 439-450. 
Warren, N. M., Piggott, M. A., Perry, E. K., and Burn, D. J. (2005). Cholinergic systems in progressive supranuclear palsy. Brain 128, 239-249.

White, O. W., Saint-Cyr, J.A., Tomlinson, R. D., and Sharpe, J.A. (1983). Ocular motor deficits in Parkinson's disease. II. Control of the saccadic and smooth pursuit systems. Brain 106, 571-587.

Williams, D. R., and Lees, A. J. (2009). Progressive supranuclear palsy: clinicopathological concepts and diagnostic challenges. Lancet Neurol. 8, 270-279.
Williams, D. R., Lees, A. J., Wherrett, J. R., and Steele, J. C. (2008). J. Clifford Richardson and 50 years of progressive supranuclear palsy. Neurology 70 , 566-573.

Zhang, Y., Gamlin, P. D., and Mays, L. E. (1991). Antidromic identification of midbrain near response cells projecting to the oculomotor nucleus. Exp. Brain Res. 84, 525-528.

Zhang, Y., Mays, L. E., and Gamlin, P. D. (1992). Characteristics of near response cells projecting to the oculomotor nucleus. J. Neurophysiol. 67, 944-960.
Conflict of Interest Statement: The authors declare that the research was conducted in the absence of any commercial or financial relationships that could be construed as a potential conflict of interest.

Received: 14 September 2010; accepted: 03 November 2010; published online: 03 December 2010.

Citation: Chen AL, Riley DE, King SA, Joshi AC, Serra A, Liao K, Cohen ML, OteroMillan J, Martinez-CondeS, Strupp Mand Leigh RJ (2010) The disturbance of gaze in progressive supranuclear palsy: implications for pathogenesis. Front. Neur. 1:147. doi: 10.3389/fneur.2010.00147

This article was submitted to Frontiers in Neuro-Otology, a specialty of Frontiers in Neurology.

Copyright (c) 2010 Chen, Riley, King, Joshi, Serra, Liao, Cohen, Otero-Millan, Martinez-Conde, Strupp and Leigh. This is an open-access article subject to an exclusive license agreement between the authors and the Frontiers Research Foundation, which permits unrestricted use, distribution, and reproduction in any medium, provided the original authors and source are credited. 